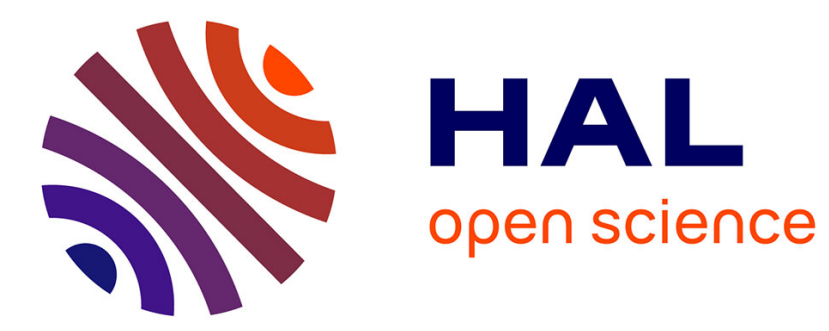

\title{
Insights on the Auxochromic Properties of Guanidinium Group
}

\author{
Ivana Antol, Zoran Glasovac, Davor Margetić, Rachel Crespo-Otero, Mario
}

Barbatti

\section{> To cite this version:}

Ivana Antol, Zoran Glasovac, Davor Margetić, Rachel Crespo-Otero, Mario Barbatti. Insights on the Auxochromic Properties of Guanidinium Group. Journal of Physical Chemistry A, 2016, 120 (36), pp.7088-7100. 10.1021/acs.jpca.6b05180 . hal-02288817

\section{HAL Id: hal-02288817 https://hal-amu.archives-ouvertes.fr/hal-02288817}

Submitted on 16 Sep 2019

HAL is a multi-disciplinary open access archive for the deposit and dissemination of scientific research documents, whether they are published or not. The documents may come from teaching and research institutions in France or abroad, or from public or private research centers.
L'archive ouverte pluridisciplinaire HAL, est destinée au dépôt et à la diffusion de documents scientifiques de niveau recherche, publiés ou non, émanant des établissements d'enseignement et de recherche français ou étrangers, des laboratoires publics ou privés. 


\title{
Insights on the Auxochromic Properties of
}

\section{Guanidinium Group}

Ivana Antol, ${ }^{1, *}$ Zoran Glasovac, ${ }^{1}$ Davor Margetić, ${ }^{1}$ Rachel Crespo-Otero ${ }^{2}$ and Mario Barbatti ${ }^{3}$

1) Division of Organic Chemistry and Biochemistry, Ruđer Bošković Institute, P.O.B. 180, HR10002, Zagreb, Croatia, Tel. No.: +38514561008

2) School of Biological and Chemical Sciences, Materials Research Institute, Queen Mary University of London, Mile End Road, London E1 4NS, UK

3) Aix Marseille Université, CNRS, ICR UMR7273, 13397 Marseille, France

\begin{abstract}
$\mathrm{UV} / \mathrm{Vis}$ spectra of phenylguanidine (PHGU) in the gas phase and in acetonitrile have been simulated by TD-DFT calculations. Several DFT hybrid and long-range corrected functionals were tested with respect to CASPT2 gas phase calculations. Solvent effects were considered using polarizable continuum model (PCM) and compared with the measured data in acetonitrile. Comparison with isoelectronic phenyl urea and related phenyltiourea was done as well. The PBE0 and long-range corrected CAM-B3LYP functionals were selected to investigate the effect of protonation on the excitation energies and absorption intensities of PHGU and several guanidine
\end{abstract}


derivatives with different aromatic chromophoric groups (naphthyl, anthracenyl, quinolinyl, anthraquinonyl and coumarinyl). Also, the effect of complexation and specific interactions through hydrogen bonds with different anions was examined. It was shown that the protonation of guanidine subunit shifts the low energy absorption bands toward higher energies (hypsochromic shift). The shift is reduced upon complexation with anions. In phenylguanidine salts, $\lambda_{\max }$ are correlated to the anion basicity and strength of H-bonding. The observed changes diminish upon increase of chromophoric size (naphthyl, anthracenyl). Theoretical predictions of UV/Vis spectra correlate well with experimentally measured spectra of selected guanidine derivatives and their salts.

\section{INTRODUCTION}

Hydrogen bonding is a ubiquitous phenomenon in nature, which is of great importance in functioning of living organisms. A vast area of supramolecular chemistry could be recognized as the "chemistry of hydrogen bonded systems". Recently, an overview of new discoveries in this research field has been published encompassing usage of hydrogen bonds from anion binding to construction of large polymeric structures. ${ }^{1}$

Due to the mobility of the proton involved in hydrogen bond, this interaction can be used for regulation of electron transfer processes. For instance, guanidine-carboxylate salt bridge formed upon arginine-aspartate hydrogen bonding interaction regulates electron transfer in some biologically important redox processes. ${ }^{2-6}$ Nocera and co-workers also showed that electron transfer rates are significantly influenced by the directionality of the salt bridge dipole. ${ }^{7}$ In such systems, electron transfer across the salt bridge is usually coupled with proton movement. 
To achieve an efficient binding of anions, various proton donating functional groups have been used, among which ureas, ${ }^{8}$ thioureas, ${ }^{9}$ amides,${ }^{10,11,12}$ amidines, ${ }^{13}$ and guanidines ${ }^{14,15,16}$ are the most common. If connected to a suitable chromophore, the anion binding will result in observable change in color as in the case of fluoride anion/pyrrolidylamidothiourea based sensor. ${ }^{17}$ In this case, the effect is related to a deprotonation of the acidic thioureas by highly basic anions, like acetate or fluoride; while less basic anions, like nitrate, perchlorate or sulphate, give small, often negligible changes. ${ }^{18,19,20}$

Guanidine functional group is especially interesting due to its acid/base properties. The specific Y-shaped structure of its protonated form allows efficient delocalization of the electrons, which results in high stability and, therefore, in its unusually high basicity. ${ }^{21,22}$ Unlike urea and thiourea, guanidine can be easily protonated and, in this form, anion binding is assisted by coulombic charge-charge attractive forces. Therefore, we can expect that guanidines bind anions significantly stronger than ureas, thioureas or amidines. This latter feature of guanidinium cation has been widely used in design of strong and selective binders for anionic guests, ${ }^{23,24}$ anion transporters, colorimetric probes, and sensors. ${ }^{25}$ Moreover, the large scientific interest on guanidine species is motivated by its presence as a substructure in many natural compounds and commercial drugs. ${ }^{26} \mathrm{~A}$ number of basic organocatalysts have been designed using guanidine as the pivotal building block. ${ }^{27,28}$ Besides that, plate-like structure of the protonated guanidine shows two opposite tendencies: its hydrophobic upper and lower parts allow even cation-cation stacking with practically no repulsion, ${ }^{29}$ while its hydrophilic edge, defined by the directionality of $\mathrm{N}-\mathrm{H}$ bonds, tends to form strong hydrogen bonds with polar molecules especially with those of similar geometry, like nitro or carboxylate groups. Although guanidine subunit is of the great 
potential, it also complicates the design of the receptor due to the increased number of the structural variables one should take care of.

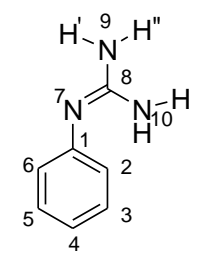

PHGU

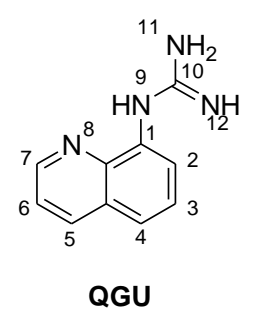

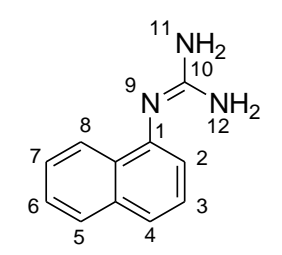

NGU

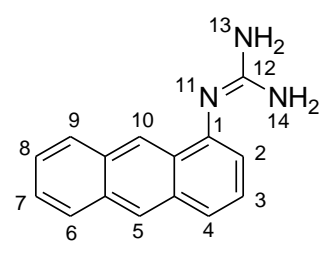

ACGU
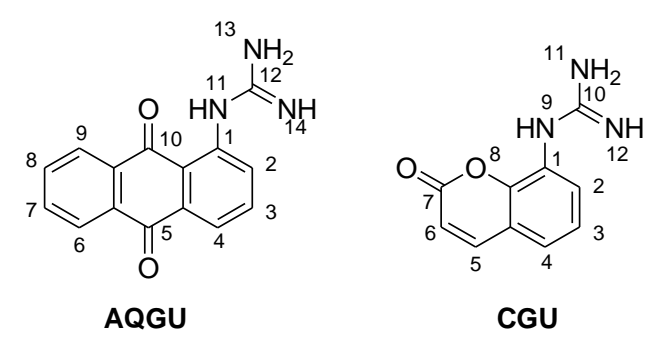

Scheme 1. Selected aromatic guanidines

Development of modern quantum chemical calculation programs and methods allows us to analyze structure of the anion receptors in detail and to gain insight on changes that occur upon anion binding. This information can be of great importance for the design of the efficient anion sensors. In this work, we explored anion binding properties of some simple aromatic guanidines (Scheme 1) and investigated structures and UV/Vis properties of the free receptor and its complexes with various anions. For this purpose, we carried out a comprehensive investigation of simulated and measured UV spectra for this class of molecules. Special emphasis is put on the orbital interactions between the guanidine subunit and chromophore identifying auxochromic properties of guanidine. These calculations have also served another purpose: to test how successfully DFT models can be employed for predicting UV/Vis properties of components for 
the light-responsive systems, where photoenergy transfer is regulated through guanidine moiety and for the potential building blocks in construction of novel guanidine based anion sensors.

\section{EXPERIMENTAL AND THEORETICAL METHODS}

Computational details. Gas-phase ground state geometries were optimized at the B3LYP/6$311+\mathrm{G}(\mathrm{d}, \mathrm{p})$ level of theory. ${ }^{30,31}$ Vibrational analyses were performed to verify the true minimum nature. Several orientations of the substituent group were tested and the lowest energy structure was further used for the calculations of the excited-state properties. The electronic absorption spectra of phenylguanidine (PHGU), were calculated by means of the time-dependent functional theory (TD-DFT) ${ }^{32}$ using different functionals: BMK $,{ }^{33} \mathrm{PBE} 0,{ }^{34} \mathrm{M} 062 \mathrm{X},{ }^{35} \omega \mathrm{B} 97 \mathrm{XD},{ }^{36} \mathrm{LC}$ BLYP $,{ }^{37,38} \mathrm{LC}-\omega \mathrm{PBE},{ }^{39,40}$ and CAM-B3LYP. ${ }^{41}$ For a recent review on the performance of different density functionals for calculation of the excitation energies in different molecules see ref. ${ }^{42}$. In addition to the default value of the $\omega$ parameter in the long-range corrected functionals, calculations with $\omega=0.2 \mathrm{a}^{-1}$ were performed. A tuning of $\omega$ parameters for different DFT functionals were conducted for different systems and the optimized values were in the range 0.17-0.21 a $\mathrm{a}^{-1} .{ }^{43} \mathrm{We}$ thought it was worthwhile to test it herein on our molecules and, indeed, it was found that there is better agreement with $E_{\max }$ from measured spectra, if the decreased $\omega=$ $0.2 \mathrm{a}^{-1}$ was used not only for LC-BLYP and LC- $\omega$ PBE, but also for CAM-B3LYP. All calculations have been performed by using $6-311+\mathrm{G}(\mathrm{d}, \mathrm{p})$ basis set.

The gas-phase TD-DFT results were compared with corresponding complete active space perturbation theory to the second order (CASPT2) results based on the aug-cc-pVDZ basis set. ${ }^{44,45,46}$ The active space consisted of 14 electrons and 11 orbitals. State averaging (SA) procedure at complete active space self-consistent field (CASSCF) and multi-state (MS) 
CASPT2 were used for calculating vertical excitation energies with up to 10 roots. The CASPT2 vertical energies were calculated by using level shift of 0.3 a.u. ${ }^{47}$ and default IPEA shift $(0.25$ a.u.). ${ }^{48}$ The same shifts have been used for the calculations of the excited states of guanidine. ${ }^{49}$ Also, in all CASPT2 calculations, the core electrons (20 electrons, 10 orbitals) were kept frozen and the oscillator strengths were calculated with the CAS state interaction method (RASSI) ${ }^{50}$ The RASSI calculations were carried out following the MS-CASPT2 calculations.

Calculated UV spectra of the guanidines and their salts at the TD-DFT level were further refined by considering the molecules into acetonitrile through the polarizable continuum model (PCM). The standard integral equation formalism (IEFPCM) and default atomic radii, ${ }^{51}$ as implemented in Gaussian09, ${ }^{52}$ were used in conjunction with PBE0 and CAM-B3LYP $\left(\omega=0.2 \mathrm{a}^{-1}\right)$ functionals.

The binding energy between guanidines (protonated form) and different anions has been calculated as the difference between the total energy of the salt and the sum of the energies of corresponding isolated guanidinium cation and anion. The Boys-Bernardi counterpoise technique $\mathrm{e}^{53,54}$ has been used to correct the inherent basis set superposition error (BSSE).

The DFT and TDDFT electronic data were obtained using Gaussian 09 program. $^{52}$ The CASPT2/CASSCF calculations were performed with Molcas 7.8 software, ${ }^{55,56,57}$ while Vega$\mathrm{ZZ}^{58}$ and Molden ${ }^{59}$ programs were used for visualization and geometry manipulations.

Experimental details. Phenylguanidine ${ }^{60}$ and 1-naphthylguanidine were prepared by converting appropriate amines to benzoylthioureas, ${ }^{61}$ followed by guanylation using hexamethyldisilazane method $^{62}$ and finally by debenzoylation and deprotonation in $30 \% \mathrm{NaOH}^{61,62}$ (Scheme 2). Synthetic details are given in the Supporting Information. Nitrate, acetate and formate salts were 
prepared by adding equimolar amount of the corresponding acid to the methanolic solution of the desired guanidine and evaporating to dryness. Formed crude salts were recrystallized from the acetonitrile.

$\mathrm{UV} /$ Vis spectra were recorded at $25^{\circ} \mathrm{C}$ using PG Instruments Ltd T80+ spectrophotometer with chemstation software. All spectroscopic studies described here were conducted in acetonitrile.
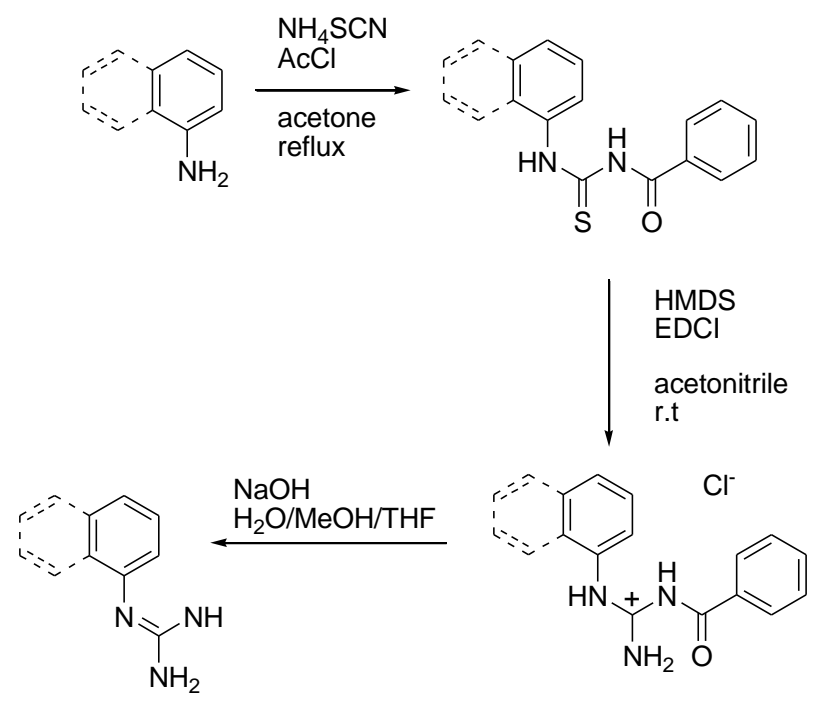

Scheme 2. Synthesis of the target aromatic guanidines.

\section{RESULTS AND DISCUSSION}

Phenylguanidine. The study of auxochromic properties of guanidinium group was started by its attachment to the simplest possible aromatic ring, benzene. Firstly, the electronic states of phenyl-guanidine (PHGU) (Scheme 1) have been characterized in the gas phase and in solvent at the TD-DFT level of theory, varying the density functionals. The gas phase results were compared with CASPT2 calculations (the vertical excitation energies, oscillator strengths and 
leading configurations, as well as figures of active orbitals at CASPT2 are given in the Supporting Information), while the inclusion of surrounding solvent effects in the DFT calculations allows direct comparison of simulated and experimentally measured UV/Vis spectra. Acetonitrile solvent has been selected because specific solute-solvent interactions are not expected there and $\mathrm{PCM}^{63}$ provides a valid approximation for the solvent effects. To study UV/Vis spectra, the nonequilibrium PCM solutions for the TD-DFT calculations were applied. ${ }^{64}$ The calculations in solutions were performed using the PBE0 and CAM-B3LYP functionals.

Table 1. Comparison of selected vertical excitation energies $\left(E_{\mathrm{exc}} / \mathrm{eV}\right)$ calculated with different density functionals. CASPT2 results are also provided. Oscillator strengths $(f)$ are given in parentheses.

\begin{tabular}{|l|c|l|c|c|}
\hline \multirow{2}{*}{ Method } & \multicolumn{2}{|c|}{$1^{\text {st }}$ exc. state } & \multicolumn{2}{l|}{ Bright state } \\
\cline { 2 - 5 } & $E_{\text {exc }} / \mathrm{V}$ & $f$ & $E_{\text {exc }} / \mathrm{eV}$ & $f$ \\
\hline Gas phase & & & & \\
\hline BMK & 5.14 & 0.020 & 5.37 & 0.283 \\
\hline PBE0 & 4.91 & 0.019 & 5.16 & 0.267 \\
\hline M062X & 5.12 & 0.019 & 5.35 & 0.281 \\
\hline$\omega B 97 X D$ & 5.07 & 0.018 & 5.36 & 0.281 \\
\hline LC-BLYP & 5.25 & 0.016 & 5.54 & 0.252 \\
\hline LC-BLYP $(\omega=0.2)$ & 4.76 & 0.017 & 5.05 & 0.242 \\
\hline LC- $\omega$ PBE & 5.21 & 0.016 & 5.53 & 0.274 \\
\hline LC- $\omega$ PBE $(\omega=0.2)$ & 4.80 & 0.016 & 5.10 & 0.290 \\
\hline CAM-B3LYP & 5.06 & 0.018 & 5.32 & 0.275 \\
\hline
\end{tabular}




\begin{tabular}{|l|l|l|l|l|}
\hline CAM-B3LYP $(\omega=0.2)$ & 4.91 & 0.018 & 5.15 & 0.129 \\
\hline CASPT2 (MS) & 4.67 & 0.045 & 5.26 & 0.505 \\
\hline Acetonitrile & & & & \\
\hline PBE0 & 4.86 & 0.027 & 5.05 & 0.360 \\
\hline CAM-B3LYP & 5.09 & 0.026 & 5.34 & 0.336 \\
\hline CAM-B3LYP(w=0.2) & 4.87 & 0.020 & 5.13 & 0.264 \\
\hline UV/vis measurements & & & 4.96 & \\
\hline
\end{tabular}

The first singlet excited state of PHGU originates from electron excitation from HOMO orbital (36a) to LUMO+1 (38a). The second excited state has HOMO-LUMO (36a-37a) character. Substitution of benzene with guanidinium group gives rise to small but nonzero oscillator strengths in contrast to the parent benzene, where $f$ for corresponding excited states is zero. The calculated excitation energy of the first excited state is $4.67 \mathrm{eV}$ using multi-state CASPT2 approach. All DFT methods give higher excitation energies up to $5.25 \mathrm{eV}$ (LC-BLYP). PBE0, $\mathrm{LC}-\omega \mathrm{PBE}(\omega=0.2)$ and CAM-B3LYP $(\omega=0.2)$ give excitation energy values lower than $5 \mathrm{eV}$ being in better match with CASPT2 values. The first observable absorption band in the spectrum of PHGU is produced by transition from the ground state to the second excited state. Its calculated oscillator strength is predicted to be 0.505 at CASPT2 level of theory. TD-DFT gives lower intensity of the first bright state than the CASPT2. The $f$ value varies from 0.129 to 0.290 , as calculated with different density functionals (Table 1). The excitation energies calculated by TD-DFT methods are between 5.05 (LC-BLYP $(\omega=0.2))$ and $5.54 \mathrm{eV}(\mathrm{LC}-\mathrm{BLYP})$; and the calculated CASPT2 values are in the same range. 
Based on the case of PHGU as well as on additional data for akin PHTU and PHUR (details in Supporting Information) we highlight that the decrease of the $\omega$ parameter in the long-range corrected functionals leads to a systematic decrease of excitation energies for all examined excited states. The decrease is the largest for the LC-BLYP and the smallest for CAM-B3LYP.

The comparison between measured and theoretically predicted excitation energies for the first bright state showed that the smallest deviations from the experimental value were obtained with the PBE0 functional. The $E_{\text {exc }}$ for PHGU is in excellent agreement (the difference is less than 0.1 $\mathrm{eV}$. The excitation energy for PHUR is overestimated by $0.22 \mathrm{eV}$, and the excitation energy of PHTU is underestimated by $0.12 \mathrm{eV}$. In the case of CAM-B3LYP all values are systematically overestimated by ca. $0.4 \mathrm{eV}$. The systematic overestimation is reduced to $0.2 \mathrm{eV}$ by the replacement of the default $\omega$ parameter with the value $0.2 \mathrm{a}_{0}^{-1}$, which is typically the expected shift between the vertical excitation and the band maximum. ${ }^{65}$ Therefore, it can be concluded that substitution effect on the absorption spectrum of PHGU is reasonably well reproduced by PBE0 and CAM-B3LYP $(\omega=0.2)$ methods.

Detailed inspection of the orbitals located at the two fragments in question (guanidine and chromophore) indicate the $n-\pi$ conjugative interaction between them. In a free neutral guanidine, the three highest occupied orbitals have electron density distributed within $\pi_{\mathrm{GU}}$ and $\mathrm{n}_{\mathrm{GU}}$ lobes, as shown in Figure 1. The interaction with benzene orbital $2 \mathrm{e}_{1 \mathrm{~g}}$ is the most intense, leading to the destabilization of the HOMO. Since the energies of LUMO orbitals in benzene and in PHGU are almost equal, the HOMO-LUMO gap in PHGU is smaller than in benzene resulting in bathochromic shift. 


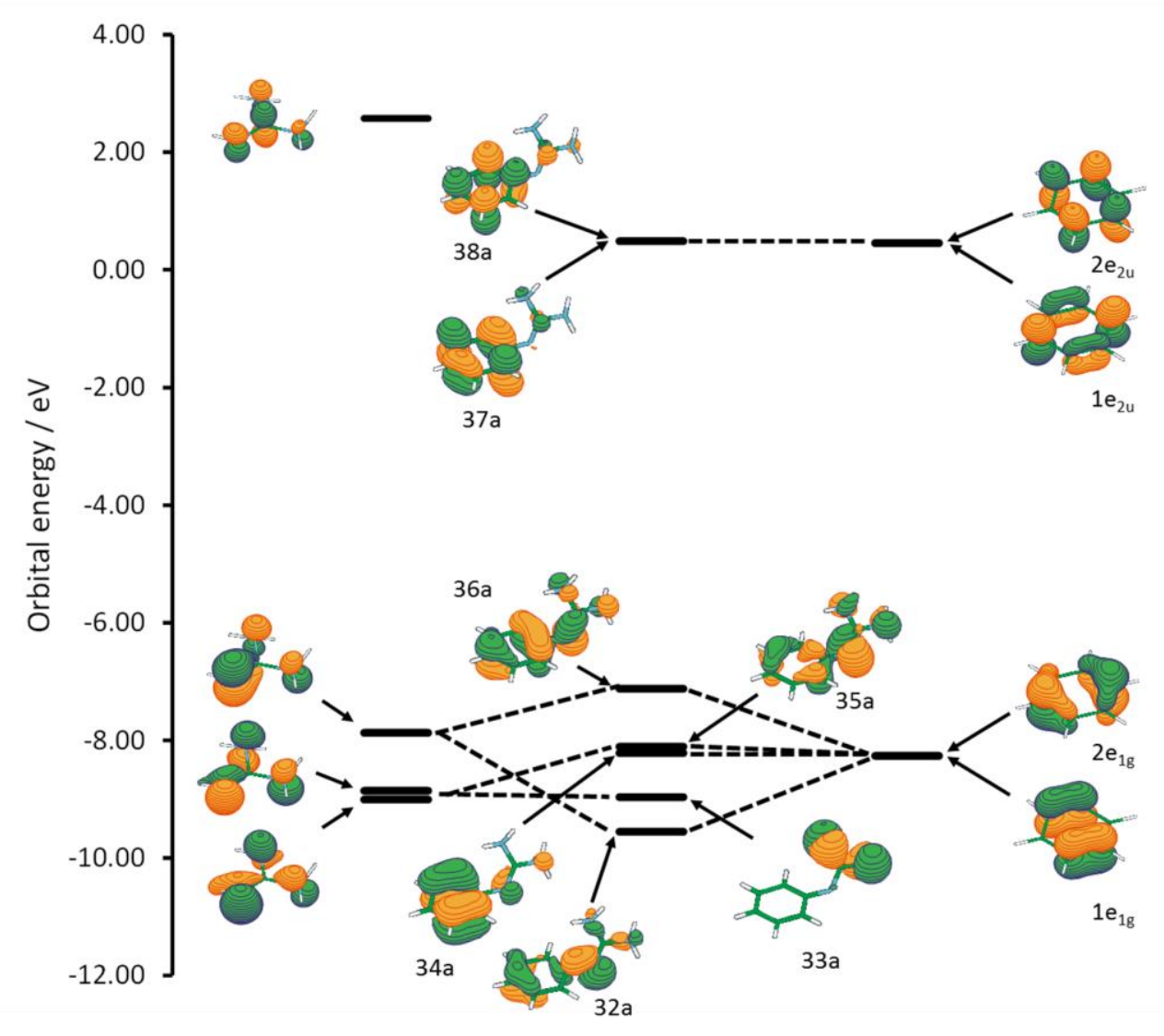

Figure 1. Orbital interactions in PHGU. The energies were taken from CAM-B3LYP $(\omega=0.2) / 6$ $311+\mathrm{G}(\mathrm{d}, \mathrm{p})$ calculation in acetonitrile.

The guanidinium group is highly basic $\left(\mathrm{p} K_{\mathrm{a}} \text { of guanidine in water: } 13.6 \mathrm{kcal} \mathrm{mol}^{-1}\right)^{66}$ and it is easily protonated under mild conditions. The optimization of the structure of protonated PHGU predicts that the guanidinium group is more perpendicular with the plane defined by phenyl ring, with respect to parent PHGU, minimizing the interactions between two $\pi$ systems. For instance, the $\mathrm{C} 8-\mathrm{N} 7-\mathrm{C} 1-\mathrm{C} 2$ dihedral angle is increased from $64.5^{\circ}$ in $\mathrm{PHGU}$ to $78.8^{\circ}$ in protonated PHGU. The C1-N7 and N7-C8 bonds are elongated by $0.044 \AA$ and $0.50 \AA$, respectively. The spectrum of protonated guanidine in acetonitrile solvent was calculated with the CAM-B3LYP $(\omega=0.2)$ and PBE0 functionals and it is convoluted with normalized Gaussian functions with $0.2 \mathrm{eV}$ standard 
deviation. A comparison with neutral PHGU is given in Figure 2a and Figure $2 \mathrm{~b}$ by using PBE0 and CAM-B3LYP $(\omega=0.2)$, respectively. These two DFT functionals predict a large blue shift of the first absorption band caused by protonation. The shift is $31 \mathrm{~nm}(0.75 \mathrm{eV})$ at the CAM$\operatorname{B} 3 \operatorname{LYP}(\omega=0.2)$ level of theory. It was also predicted that the intensity of the band is decreased by protonation. Still at the CAM-B3LYP $(\omega=0.2)$ level, the calculated oscillator strength of the bright state in neutral PHGU was 0.342 and in protonated $\mathrm{PHGUH}^{+}$it was 0.131 , a reduction of $\Delta f=0.21$. The PBE0 values for the shifts obtained by protonation are very similar: $\Delta \lambda_{\max }=27$ $\mathrm{nm}(0.62 \mathrm{eV})$ and $\Delta f=0.12$.

Protonation of guanidine subunit leads to removal of the $\mathrm{n}_{\mathrm{GU}}-\pi$ interaction by converting $\mathrm{n}_{\mathrm{GU}}$ orbital to a $\sigma$-bond, thus diminishing interactions between fragments. Indeed, Mayer bond orders, calculated for the guanidine-chromophore junction bond in PHGU, decrease from ca 1.2 to ca 1.0 upon protonation. In line with that, second order perturbation analysis within the NBO basis shows electron density donation from $\mathrm{n}_{\mathrm{GU}}$ lone pair to the $\pi^{*}(\mathrm{C} 1-\mathrm{C} 2) \mathrm{NBO}$ located at the chromophore contributing with $16.9 \mathrm{kcal} . \mathrm{mol}^{-1}$ and this interaction is practically removed upon protonation. Additionally, protonation of the guanidine subunit reduces the extent of $\pi_{\mathrm{chr}}-\pi_{\mathrm{GU}}$ interaction by stabilizing $\pi_{\mathrm{GU}}$ orbital due to an electrostatic effect and translation of guanidine orbitals from $\mathrm{C}_{1}$ to $\mathrm{C}_{3}$ symmetry group (if considered as a separate fragment). Besides that, torsional angle between chromophore and guanidine planes is practically $90^{\circ}$, indicating complete absence of conjugation. Consequently, the frontier orbitals as well as UV spectra of protonated forms look more like for the isolated chromophore.

To check the consistency of theoretical prediction, $5 \times 10^{-5} \mathrm{M}$ solution of PHGU in acetonitrile was titrated by $5 \times 10^{-4}$ trifluormethanesulfonic acid. After addition of one equivalent of the acid, 
UV spectra did not change anymore, indicating complete protonation of the neutral guanidine and absence of any other protonation site. The spectra recorded as a titration starting and end point are shown in Figure 2c. The blue shift between the neutral and the protonated species is 21 $\mathrm{nm}(0.48 \mathrm{eV})$. Thus, the calculated spectra for the neutral and protonated phenylguanidine are in fair accordance with the measured ones considering the positions of $\lambda_{\max }$. The calculated ratios between oscillator strengths of first bright excited state in neutral and in protonated form $f(\mathrm{PHGU}) / f\left(\mathrm{PHGUH}^{+}\right)$are 2.6 and 1.5 for CAM-B3LYP $(\omega=0.2)$ and PBE0 methods, respectively. The latter is in excellent agreement with experimentally obtained value: the area of the first experimental band is 0.399 for the neutral and 0.266 for the protonated giving the ratio of 1.5. 
(a)

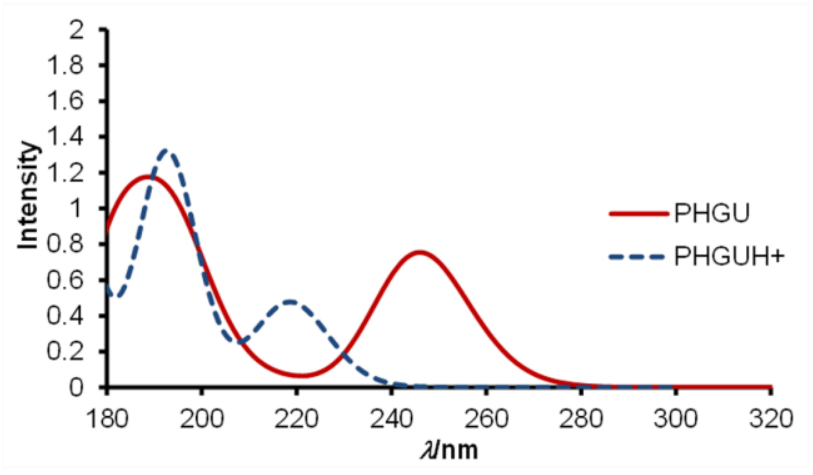

(b)

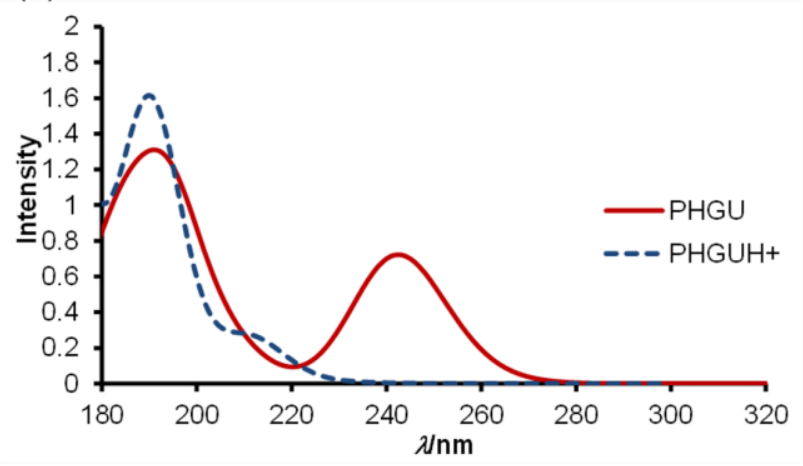

(c)

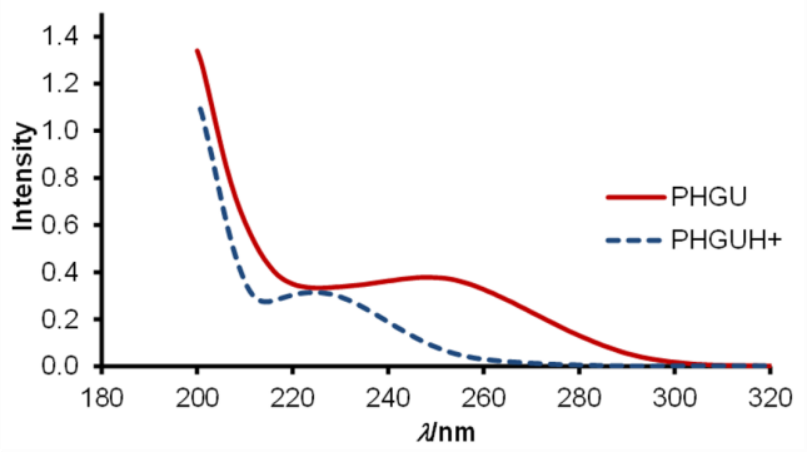

Figure 2. Comparison between UV/Vis spectra of neutral and protonated PHGU: (a) Theoretical prediction using PBE0, (b) Theoretical prediction using CAM-B3LYP $(\omega=0.2)$, and c) Experimentally measured spectra obtained by protonation of the neutral PHGU with trifluoromethanesulfonic acid in acetonitrile. 
As a next step in investigating auxxochromic effect of guanidinium group on the chromophore, we have analyzed two processes that occur upon hydrogen bond formation between guanidinium cation and anion: charge compensation and deprotonation of the guanidine subunits. We have approached this problem by computing the absorption spectrum for salts formed from complexation of $\mathrm{PHGUH}^{+}$with $\mathrm{F}^{-}, \mathrm{HCOO}^{-}, \mathrm{CH}_{3} \mathrm{COO}^{-}, \mathrm{NO}_{3}^{-}$, and $\mathrm{CF}_{3} \mathrm{SO}_{3}^{-}$. Since both PBE0 and CAM-B3LYP $(\omega=0.2)$ functionals gave similar results, only the calculations performed with TD-DFT CAM-B3LYP $(\omega=0.2)$ in acetonitrile will be discussed further in this text. Complete set of the PBE0 data ( $E_{\text {exc }}, f$, leading configurations, XYZ coordinates and comparison with experimentally available data) can be found in Supporting Information.

Two different sites of anion bonding were examined (Scheme 3). An anion can approach the guanidinium group forming a H-bonding through $\mathrm{N} 7 \mathrm{H}$ and $\mathrm{NH}$ ' bonds (complexation site 1) or through $\mathrm{N10H}$ and N9H" bonds (complexation site 2). Moreover, different monovalent anions were considered varying their basicity: $\mathrm{F}^{-}>\mathrm{HCOO}^{-} \approx \mathrm{CH}_{3} \mathrm{COO}^{-}>\mathrm{NO}_{3}^{-}>\mathrm{CF}_{3} \mathrm{SO}_{3}^{-}$. In all cases, the structures where an anion interacts through the complexation site 1 are more stable. Therefore, only bonding of different anions to PHGU in the site 1 was used in all subsequent TD-DFT calculations. 


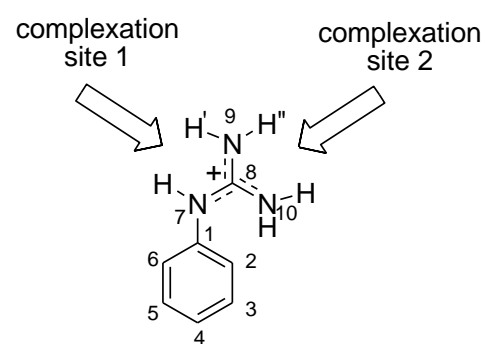

PHGUH $^{+}$

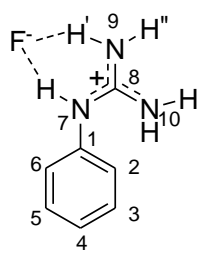

PHGU.HF

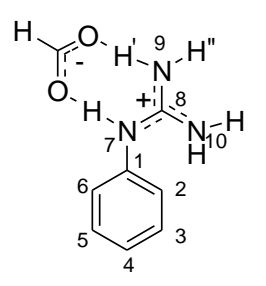

PHGU.HCOOH

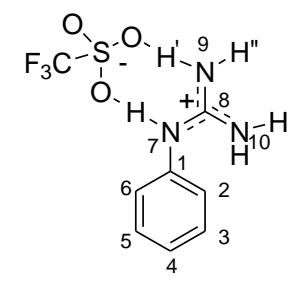

PHGU $\cdot \mathrm{CF}_{3} \mathrm{SO}_{3} \mathrm{H}$

PHGUHCOOH

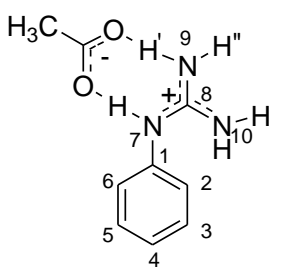

PHGU $\mathrm{CH}_{3} \mathrm{COOH}$

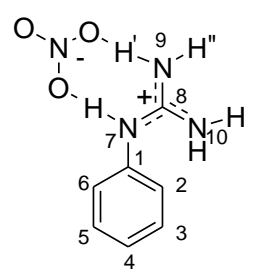

$\mathrm{PHGU} \cdot \mathrm{HNO}_{3}$

Scheme 3. Protonated phenylguanidine and its salts with $\mathrm{F}^{-}, \mathrm{COOH}^{-}, \mathrm{CH}_{3} \mathrm{COOH}^{-}, \mathrm{NO}_{3}^{-}$and $\mathrm{CF}_{3} \mathrm{SO}_{3}{ }^{-}$ions.

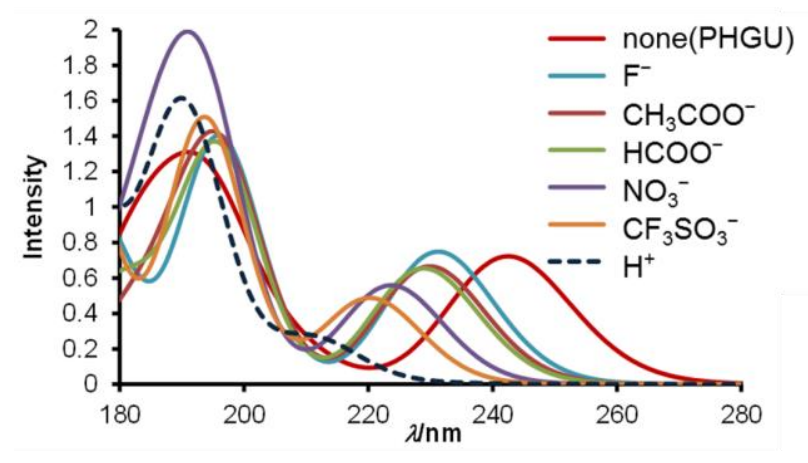

Figure 3. Comparison between simulated UV/Vis spectra $(\mathrm{CAM}-\mathrm{B} 3 \mathrm{LYP}(\omega=0.2)$ method) of neutral PHGU and guanidinium salts with different counter ions.

The results of these calculations are shown in Figure 3 and Table 2. All investigated PHGU salts have the first absorption band between 210 and $250 \mathrm{~nm}$ and they are blue shifted with respect to the first band in parent PHGU. The shift is smaller than the corresponding shift for protonated

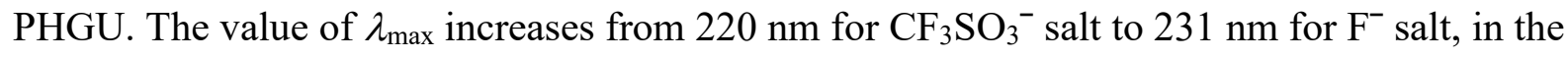


sequence $\mathrm{CF}_{3} \mathrm{SO}_{3}{ }^{-}<\mathrm{NO}_{3}{ }^{-}<\mathrm{HCOO}^{-}<\mathrm{CH}_{3} \mathrm{COO}^{-}<\mathrm{F}^{-}$. Also the calculated oscillator strength increases from 0.244 for $\mathrm{CF}_{3} \mathrm{SO}_{3}{ }^{-}$to 0.371 for $\mathrm{F}^{-}$salt. It should be stressed that these shifts correlate to the anion basicity and binding energies of $\mathrm{PHGUH}^{+}$with anions (Table 2). The highest binding energy was calculated for fluoride and acetate anions, which are the most basic anions in the considered set. In spite of the relatively high basicity of these two anions, optimizations in acetonitrile do not predict full proton transfer from the guanidinium cation to the anion; although a significant N-H bond elongation takes place (Table 2). Thus, N7-H bond length assumes values of 1.064 and $1.057 \AA$ for fluoride and acetate complexes, which are 0.050 and $0.043 \AA$ larger than for the isolated phenylguanidinium cation. The analogous bond elongation induced by nitrate binding amounts to only $0.019 \AA$. This partial deprotonation is also weakest for acidic anion $\mathrm{CF}_{3} \mathrm{SO}_{3}{ }^{-}$and its spectrum is similar to the spectra of protonated PHGU. For highly basic anions, as $\mathrm{F}^{-}$and $\mathrm{CH}_{3} \mathrm{COO}^{-}$where partial deprotonation is more emphasized, their maxima of the first band are shifted toward neutral PHGU.

Table 2. Comparison of the anion binding energy (BE) to protonated PHGU with the shift of the first absorption band of different salts with respect to the protonated PHGU in acetonitrile. The $\mathrm{p} K_{\mathrm{a}}$ of conjugated acids HA measured in water are given as well.

\begin{tabular}{|l|l|l|l|l|l|}
\hline Anion & $\Delta E_{\text {exc }} / \mathrm{eV}^{\mathrm{a}}$ & $\Delta \lambda_{\max }{ }^{\mathrm{a}}$ & $\Delta r(\mathrm{~N} 7-\mathrm{H})^{\mathrm{b}} / \AA$ & $\mathrm{BE} / \mathrm{kcal} \mathrm{mol}^{-1}$ & $\mathrm{p} K_{\mathrm{a}}(\mathrm{HA})^{\mathrm{c}}$ \\
\hline $\mathrm{CF}_{3} \mathrm{SO}_{3}^{-}$ & 0.26 & 9 & 0.014 & -12.0 & $-5.9^{67}(2.60)$ \\
\hline $\mathrm{NO}_{3}{ }^{-}$ & 0.35 & 13 & 0.019 & -14.4 & $-1.64^{68}(8.80)$ \\
\hline $\mathrm{HCOO}^{-}$ & 0.47 & 18 & 0.037 & -19.9 & $3.75^{69}$ \\
\hline $\mathrm{CH}_{3} \mathrm{COO}^{-}$ & 0.50 & 19 & 0.043 & -21.6 & $4.76^{69}(23.51)$ \\
\hline $\mathrm{F}^{-}$ & 0.53 & 20 & 0.050 & -21.9 & $3.17^{69}$ \\
\hline
\end{tabular}

a) with respect to protonated PHGU 
b) calculated as the difference with respect to the non-coordinated guanidinium cation $\mathrm{PHGUH}^{+}$ c) $\mathrm{p} K_{\mathrm{a}}$ values in acetonitrile are given in parentheses. ${ }^{70}$

To shed more light on the extent of UV-absorption changes caused by guanidine/ion interaction, we followed the reaction paths for three processes: (i) stepwise approach of the acetate anion, (ii) proton exchange between phenylguanidinium cation and acetate anion within ion pair, and (iii) departure of the neutral acetic acid. Process (i) encompasses partial charge compensation (shielding) with concomitant partial deprotonation of the guanidine subunit. These two processes were separated by comparison of two scans for the approach of the acetate anion toward the protonated phenylguanidine: relaxed and "semi-rigid" (partially relaxed). The "semi-rigid" scan was conducted by fixing the geometry of the guanidinium subunit that corresponds to the optimized free phenylguanidinium cation. In this case, no elongation of the NH bonds was allowed preventing thus partial deprotonation process. The scans were carried out at B3LYP/6$31 \mathrm{G}(\mathrm{d})$ level of theory, while UV spectra were calculated using CAM-B3LYP $(\omega=0.2)$ at seven selected partially optimized scan points (Figure SI4 in Supplemental Material). ${ }^{71}$ The results were compared to the fully relaxed scan in which partial deprotonation takes place. Both scans were started from the optimized structure of the phenylguanidinium acetate complex and acetate anion was gradually displaced until distance between $\mathrm{C} 10$ and carboxylate carbon atom reached $6 \AA$. The acetate induced bathochromic shift was calculated as the difference in $\lambda_{\max }$ between the first and last point of the scan. Both scans predicted similar anion induced bathochromic shift amounting to 7 and $6 \mathrm{~nm}$ for the relaxed and semi-rigid scan, indicating minor influence of the partial deprotonation. Since the UV spectrum of the phenylguanidinium acetate is in good 
agreement with the experimental spectrum, we conclude that the acetate induced batochromic shift is primarily due to the electrostatic interaction between two charged species.

The second minimum of the phenylguanidinium acetate complex, which is formed by association of two neutral species (non-ionized complex, Scheme 4), was also optimized and the calculated first $\lambda_{\max }$ is at $249 \mathrm{~nm}$, which is significantly higher than the experimental value $(236 \mathrm{~nm})$. Thus, this structure does not contribute significantly to the UV spectra of the phenylguanidinium acetate salt.

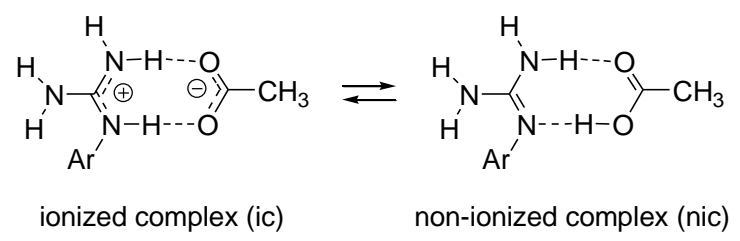

Scheme 4. Two minima of the guanidinium acetate salts.

Extension of aromatic ring: naphthalene and anthracene. The simulated spectra of 1naphthylguanidine (NGU, structure shown in Scheme 1) is characterized by three bands (Figure 4a). A very weak absorption is featured around $305 \mathrm{~nm}$ from HOMO-LUMO transition. There are two intense bands located at 230 and $203 \mathrm{~nm}$, which are strongly overlapped. The former band is dominated by single transition from the ground state to the excited state with $E_{\mathrm{exc}}=5.39$ $\mathrm{eV}$ and $f=0.6561$ (leading configuration is $47 \mathrm{a}-50 \mathrm{a}$, orbitals are shown in Supporting Info). Excitations to several excited states with calculated oscillator strengths between 0.1 and 0.25 contribute to the third band (maximum at $203 \mathrm{~nm}$ ). In the protonated form, the first excited sate 
transition (HOMO-LUMO, $\left.E_{\mathrm{exc}}=4.41 \mathrm{eV}\right)$ is shifted to higher energies by $0.35 \mathrm{eV}(24 \mathrm{~nm})$ with respect to the parent NGU. The intensity of the related band decreases, in accordance to the observed changes observed upon protonation of PHGU. In the region between 190 and $250 \mathrm{~nm}$, there is only one band, mostly dominated by a transition from the ground state to the third excited state (HOMO-LUMO+1, $\left.E_{\mathrm{exc}}=5.70 \mathrm{eV}, f=1.288\right)$.

The theoretical predictions are compared with the measured UV-Vis spectra of NGU and its protonated form (Figure 4b). Clearly, there is a qualitative agreement between theoretical predictions and measured data. Experimentally observed hypsochromic shift of the lowest energy band upon protonation $(24 \mathrm{~nm})$ is in excellent agreement with predictions. Two overlapping bands were measured for the neutral NGU between 200 and $250 \mathrm{~nm}$, as predicted by the calculation. However, in the experiment overlapping is more pronounced ( $\lambda_{\max }$ are closer) than predicted and the intensity of these two bands differs substantially. The rise of sharp band upon protonation is well defined experimentally and theoretically $\left(\lambda_{\max }=222 \mathrm{~nm}\right.$ (measured) and 215 $\mathrm{nm}$ (calculated)). 

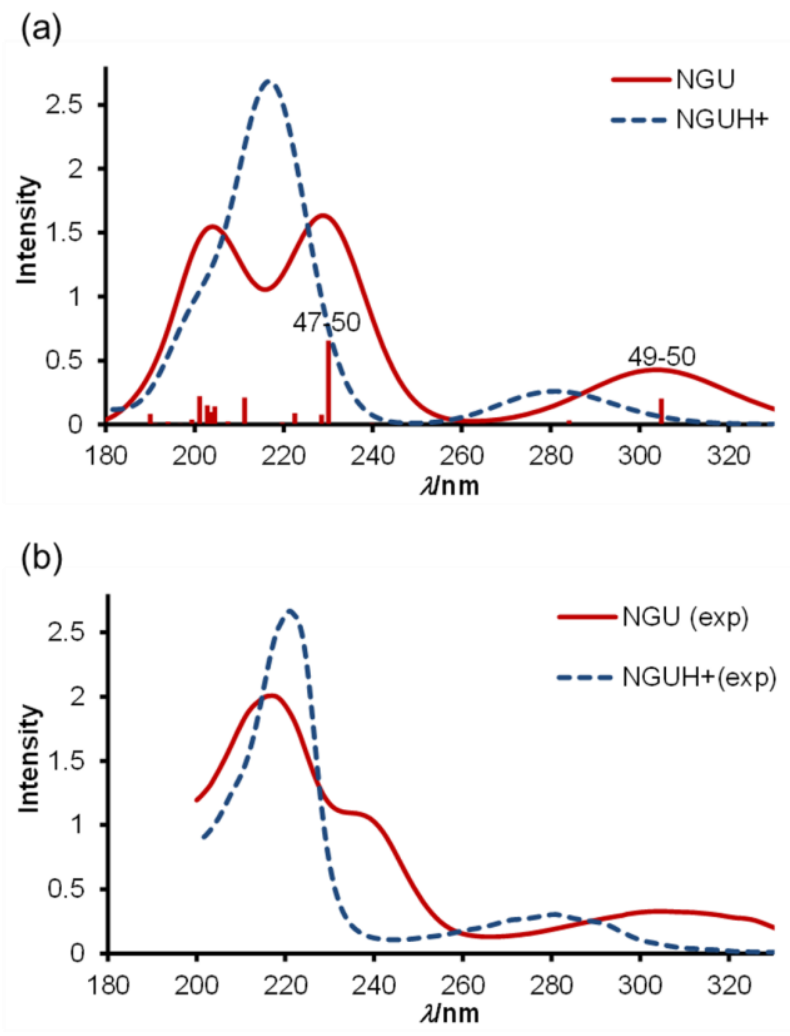

Figure 4. (a) The simulated absorption spectra of $\mathrm{NGU}$ and $\mathrm{NGUH}^{+}$in acetonitrile at the TDCAM-B3LYP $(\omega=0.2) / 6-311+\mathrm{G}(\mathrm{d}, \mathrm{p})$ level of theory. (b) Experimental spectra of NGU and its protonated form in acetonitrile.

The absorption spectra of 1-naphthyl-guanidinium salts with $\mathrm{F}^{-}, \mathrm{HCOO}^{-}, \mathrm{CH}_{3} \mathrm{COO}^{-}, \mathrm{NO}_{3}^{-}$, and $\mathrm{CF}_{3} \mathrm{SO}_{3}{ }^{-}$anions were also calculated. Structural relationship among aromatic system, guanidinium group and anion, as well as complexation site, is identical to what was found in phenyl-guanidinium salts. However, inspection of the simulated UV/Vis spectra (Figure 5) reveals that the effect of complexation on the $\lambda_{\max }$ is less pronounced than in the case of PHGU. The position of the HOMO-LUMO band maxima for salts with $\mathrm{CF}_{3} \mathrm{SO}_{3}{ }^{-}$and $\mathrm{NO}_{3}{ }^{-}$anions is almost identical to the $\lambda_{\max }$ calculated for protonated NGU. Calculated $E_{\mathrm{exc}}$ for the first excited state in protonated $\mathrm{NGU}$ and its salts with $\mathrm{CF}_{3} \mathrm{SO}_{3}{ }^{-}$, and $\mathrm{NO}_{3}{ }^{-}$are $4.41,4.40$, and $4.41 \mathrm{eV}$, 
respectively (Table 3). In the case of complexes with $\mathrm{HCOO}^{-}, \mathrm{CH}_{3} \mathrm{COO}^{-}$and $\mathrm{F}^{-}$, the $\mathrm{HOMO}-$ LUMO transition is shifted toward lower energies. The shift is decreased with respect to the complexation effects found in PHGU.

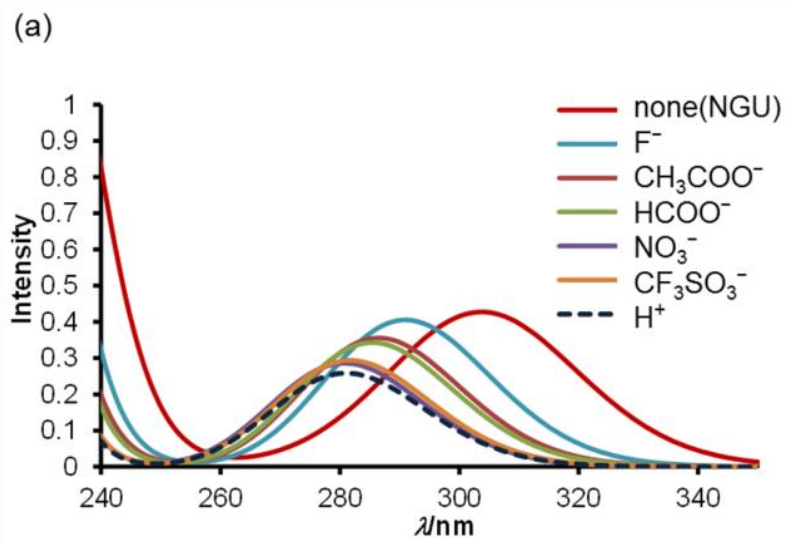

Figure 5. Comparison between simulated UV/Vis spectra by using CAM-B3LYP $(\omega=0.2)$ functional for the first weak absorption band of neutral NGU and its salts with different counter ions. Protonated $\mathrm{NGUH}^{+}$is given as dashed lines.

Table 3. Calculated excitation energies $E_{\text {exc }}(\mathrm{eV})$ for the lowest excited state. CAM-

$\operatorname{B3LYP}(\omega=0.2)$ density functional was used in conjunction with $6-311+\mathrm{G}(\mathrm{d}, \mathrm{p})$ basis set. Solvent $=$ acetonitrile. $\mathrm{p} K_{\mathrm{a}}$ of the investigated arylguanidinium cations $\left(\mathrm{BH}^{+}\right)$and complexation energies between acetate anion and protonated guanidines are given as well.

\begin{tabular}{|l|l|l|l|l|l|l|l|l|l|l|}
\hline Chromophore & $\begin{array}{l}\mathrm{GU}( \\
\text { neutr } \\
\text { al) }\end{array}$ & $\mathrm{CH}_{3} \mathrm{COO}^{-}$ & $\mathrm{F}^{-}$ & $\mathrm{HCOO}^{-}$ & $\mathrm{NO}_{3}^{-}$ & $\mathrm{CF}_{3} \mathrm{SO}_{3}^{-}$ & $\begin{array}{l}\mathrm{GU}(\mathrm{p} \\
\text { roton } \\
\text { ated) }\end{array}$ & $\begin{array}{l}\mathrm{p} K_{\mathrm{a}}( \\
\left.\mathrm{BH}^{+}\right) \\
\text {calc }\end{array}$ & $\begin{array}{l}\mathrm{BE} / \\
\mathrm{kcal} \\
\mathrm{mol}^{-1}\end{array}$ & $\begin{array}{l}E_{\mathrm{rel}^{\mathrm{c}}} / \\
\mathrm{kcal} \\
\mathrm{mol}^{-1}\end{array}$ \\
\hline Benzene & $\begin{array}{l}4.87( \\
5.13) \\
\mathrm{a}\end{array}$ & $\begin{array}{l}5.16(5.40) \\
\mathrm{a}\end{array}$ & $\begin{array}{l}5.12 \\
(5.3 \\
7)^{\mathrm{a}}\end{array}$ & $\begin{array}{l}5.17(5 . \\
42)^{\mathrm{a}}\end{array}$ & $\begin{array}{l}4.10( \\
5.54) \\
\mathrm{a}\end{array}$ & $\begin{array}{l}5.28(5.6 \\
3)^{\mathrm{a}}\end{array}$ & $\begin{array}{l}(5.89 \\
)^{\mathrm{a}}\end{array}$ & $\begin{array}{l}20.2 \\
(20.0 \\
)^{\mathrm{b}}\end{array}$ & -21.6 & -2.60 \\
\hline
\end{tabular}




\begin{tabular}{|l|l|l|l|l|l|l|l|l|l|l|}
\hline Naphthalene & 4.07 & 4.33 & 4.26 & 4.34 & 4.41 & 4.40 & 4.41 & $\begin{array}{l}19.6 \\
(19.4 \\
)^{\mathrm{b}}\end{array}$ & -21.5 & -1.64 \\
\hline Anthracene & 3.21 & 3.32 & 3.32 & 3.33 & 3.35 & 3.34 & 3.34 & 19.4 & -21.4 & -1.54 \\
\hline Anthraquinone & 2.95 & 3.33 & 3.34 & 3.34 & 3.38 & 3.38 & 3.47 & 18.0 & -17.7 & -1.98 \\
\hline Qquinoline & 3.77 & 4.02 & 4.03 & 4.03 & 4.07 & 4.08 & 4.12 & 19.4 & -19.3 & -3.53 \\
\hline Coumarine & 3.75 & 4.24 & 4.15 & 4.25 & 4.25 & 4.28 & 4.28 & 19.3 & -21.9 & -0.58 \\
\hline
\end{tabular}

a) the bright state

b) $\mathrm{p} K_{\mathrm{a}}$ of the protonated phenyl- and naphthylguanidine were measured by competitive titration against two reference bases. Accuracy of the measurements was estimated to \pm 0.3 . Details of the measurements are given in Supporting Information

c) Relative stabilities $\left(E_{\text {rel }}\right)$ of two minima of the guanidinium acetate salts (Scheme 4) with respect to the proton movement within the hydrogen bond $E_{\text {rel }}=E_{\text {tot }}(\mathrm{ic})-E_{\text {tot }}($ nic $)$

Further extension of the aromatic system to three condensed aromatic rings was studied on the 1-anthracenylguanidine (ACGU, Scheme 1). The simulated spectra of neutral ACGU, its protonated form and different antracenyl-guanidinium salts are shown in Figure 6. Excitation energies for the first excited state (HOMO-LUMO) are collected in Table 3. The overall pattern of the spectrum for ACGU calculated in acetonitrile (Figure 6a) is similar to the spectrum of PHGU. There are two bands: one very intense between 220 and $270 \mathrm{~nm}\left(\lambda_{\max }=252 \mathrm{~nm}\right)$ with the main contribution from the excitation to the sixth excited singlet state $(f=1.515)$, and the other very weak between 360 and $410 \mathrm{~nm}\left(\lambda_{\max }=385 \mathrm{~nm}, f=0.1442\right.$, HOMO-LUMO transition $)$. Variations in $\lambda_{\max }$ values caused by protonation are smaller than in PHGU. 
(a)

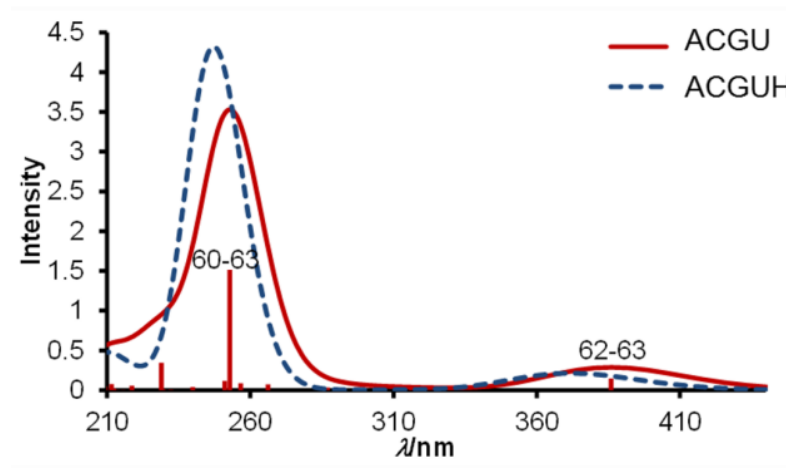

(b)

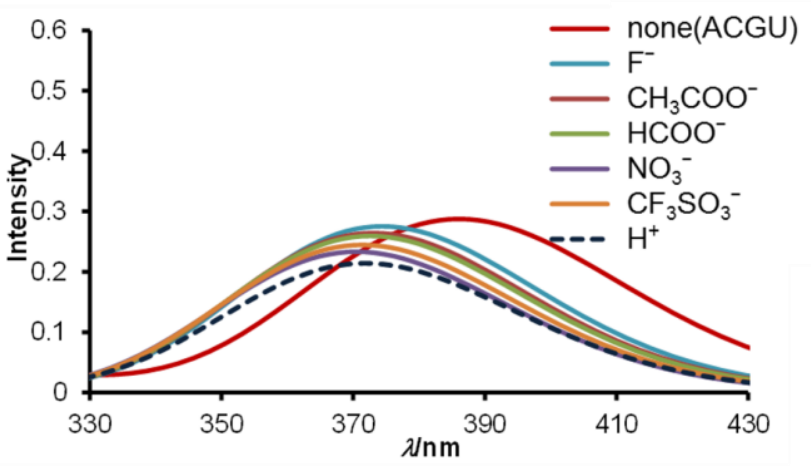

Figure 6. (a) The simulated absorption spectrum of ACGU in acetonitrile at theTD-CAM$\operatorname{B} 3 \operatorname{LYP}(\omega=0.2) / 6-311+\mathrm{G}(\mathrm{d}, \mathrm{p})$ level of theory. The absorption spectrum of protonated ACGU is given as dashed line. (b) The comparison of the first weak absorption band of neutral ACGU and its salts with different counter ions.

The effect of the complexed anions on the UV spectra significantly decreases from phenyl to anthracenyl derivative. Thus, the first absorption band shift upon acetate binding amounts to 1.1 $\mathrm{eV}$ (phenyl), $0.12 \mathrm{eV}$ (naphthyl), and $0.02 \mathrm{eV}$ (anthracenyl), which corresponds to 64, 35, and 15 $\%$ of the protonation induced shift (difference between neutral and protonated form). (Table 3 ). The results for the phenylguanidine overestimate the experimental results, where acetate induced bathochromic shift contributes $44 \%$ of deprotonation process. Evidently, anion induced batochromic shift is due to formation of the complex and not to the deprotonation of the guanidine. This is somewhat surprising having in mind the relatively high basicity of the acetate anion in acetonitrile $\left(\mathrm{p} K_{\mathrm{a}}\left(\mathrm{CH}_{3} \mathrm{COOH}\right)=23.5^{70}\right)$. In contrast, the experimental data for NGU and its salts show the maximum of the first band either around $305 \mathrm{~nm}$ (neutral, acetate and fluoride) or around $281 \mathrm{~nm}$ (protonated form, nitrate and trifluormethansulfonate). 
This finding corresponds to the two-state situation: protonated and deprotonated form depending on the basicity of the anions. Measured $\mathrm{p} K_{\mathrm{a}}$ of the 1 -naphthylguanidine is $19.4 \pm 0.2$, which is ca 0.5 lower than that of phenylguanidine. Therefore, it is of no surprise that the former guanidine undergoes deprotonation by acetate and fluoride more readily than the latter one. The first band in UV spectra of the formate salt is slightly shifted and broadened with respect to the nitrate (protonated system) and centered at $287 \mathrm{~nm}$. This position corresponds to the hydrogen bonded ion pair in which no proton transfer from the guanidinium cation to the formate anion yet happened (ionic complex). It is well known that the formate anion is less basic than the acetate ${ }^{69}$ and the difference in their basicities (Table 2) is apparently sufficient to regulate preferential structure upon anion binding. The other investigated guanidines are even less basic than 1naphthylguanidine and, similarly, full deprotonation by fluoride, acetate and formate is expected, while other anions are significantly less basic and most likely will give the spectra of the protonated form.

Quinoline, anthraquinone and cumarine derivatives. Quinoline, anthraquinone and coumarine are heteroaromatic chromophores which have the possibility of H-bond interactions with guanidine subunit attached to $\mathrm{C} 1$ carbon atom of chromophore (Scheme 1). Indeed, in the optimized structures, guanidine subunit is oriented parallel to the chromophore aromatic system. For instance, in 8-quinolinylguanidine (QGU, Scheme 1) the dihedral angle C10-N9-C1-C2 amounts to $0.5^{\circ}$, while corresponding dihedral angles in CGU and AQGU are $3.0^{\circ}$ and $1.6^{\circ}$, respectively. Moreover, the N9-H bond is tilted toward the nitrogen lone pair on quinoline subunit, establishing classical hydrogen bond, while the imino nitrogen atom is oriented in opposite direction, allowing for non-classical C2-H...N11 H-bonding interaction. In fact, atoms in molecules (AIM) analysis of the quinolinylguanidine identifies $(3,-1)$ bond critical point 
between N12 and C2-H (Figure SI5) with the values of 0.07 and 0.024 for the $\rho_{\mathrm{b}}$ and $\nabla^{2} \rho_{\mathrm{b}}$, respectively, values typical for the non-bonding component of the hydrogen bonding interaction. ${ }^{72}$ Surprisingly, we were unable to locate the corresponding bond critical point that would confirm C-H...N hydrogen bonding in the 1-guanidylathraquinone. The same orientation of guanidine group is found in both anthraquinone and coumarine derivative.

Protonation at the guanidine subunit removes the non-classical hydrogen bonding interaction and increases the repulsion between guanidinium and chromophore moieties, which in turn leads to the increase in the dihedral angle C10-N9-C1-C2 to 29.2, 34.6, and 60.8 in $\mathrm{QGUH}^{+}, \mathrm{AQGUH}^{+}$, and $\mathrm{CGUH}^{+}$, respectively. This is not surprising since the amino N9-H...O hydrogen bond in coumarine is expected to be the weakest of all considered intramolecular hydrogen bonds due to the interaction with ether-type oxygen atom. Consequently, complexation with anions in quinoline and anthraquinone goes into position 2 and, in the case of coumarine salt, which has a structure similar to what was found in PHGU, NGU and ACGU, the anion sits in position 1 (for example, see CGUHF in Scheme 5). Both anthraquinoyl- and quinolinyl-guanidines could also form "site 1" complexes at expense of hydrogen bond cleavage, but formation of these complexes is less likely. Difference between "site 1" and "site 2" complexes in anthraquinone derivatives amounts to ca $2 \mathrm{kcal} \mathrm{mol}^{-1}$, as calculated at the CAM-B3LYP $(\omega=0.2)$ level of theory. Since the difference corresponds to $97: 3$ ratio according to the Boltzman's distribution, we do not expect significant contribution of second isomer to the absorption spectrum. 


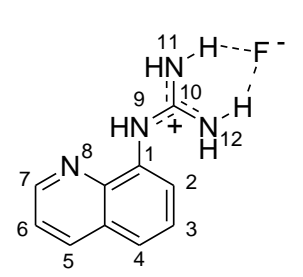

QGU·HF

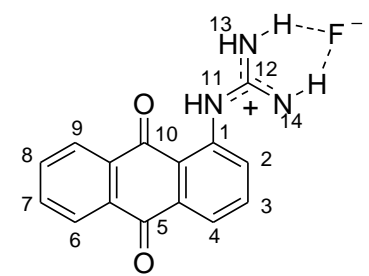

AQGU'HF

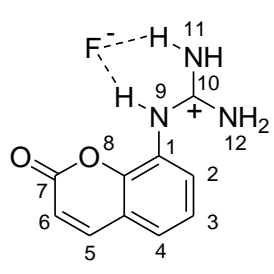

CGU·HF

Scheme 5. Different complexation sites.

TD-DFT simulations of absorption spectra for QGU, AQGU, CGU and their protonated forms in acetonitrile are given in Figure 7. As already found in PHGV, the absorption spectrum of QGU (Figure 7a) has two bands. The weak band with $\lambda_{\max }=330 \mathrm{~nm}$ is related to the excitation to the first excited state $\left(E_{\mathrm{exc}}=3.77 \mathrm{eV}, f=0.143\right)$. Excitation to the fourth excited state $\left(E_{\mathrm{exc}}=5.19 \mathrm{eV}\right.$, $f=0.634$ ) dominates the strong band with $\lambda_{\max }=233 \mathrm{~nm}$. Protonation of QGU resulted in a blue shift of both bands. The first band is shifted by $30 \mathrm{~nm}$, and the second maximum is shifted by 5 nm (Figure 7a). 
(a)

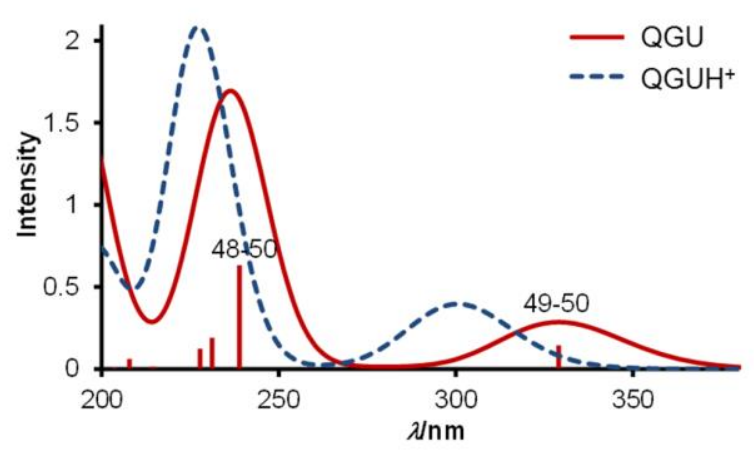

(c)

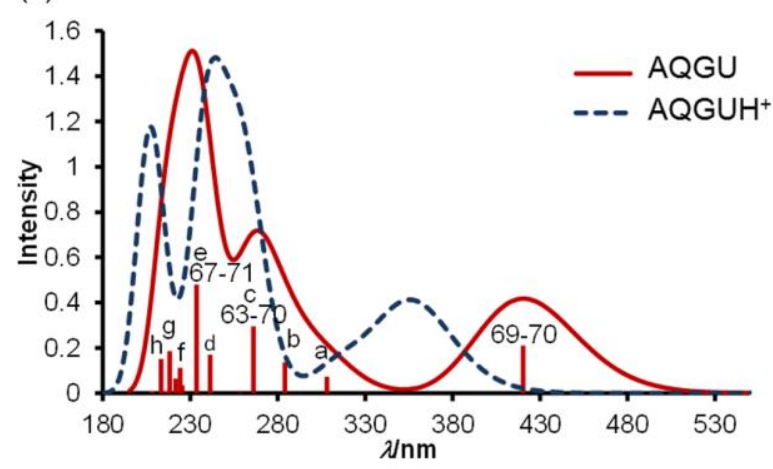

(e)

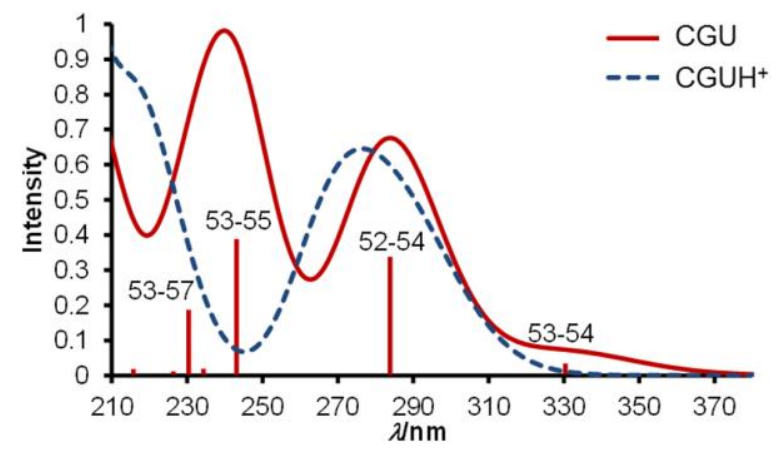

(b)

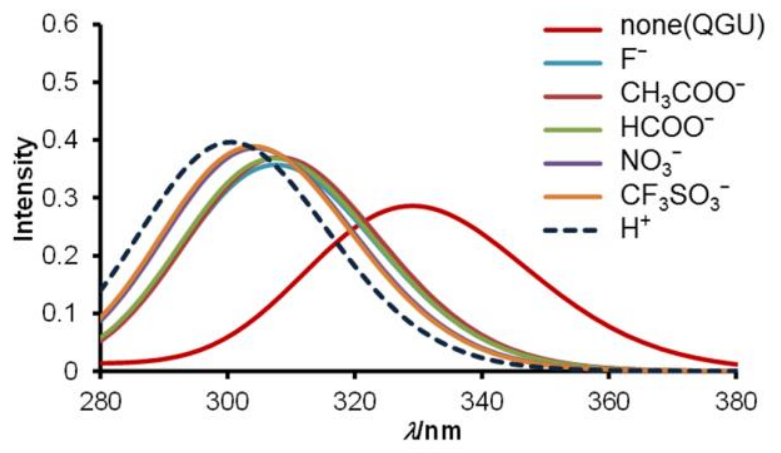

(d)

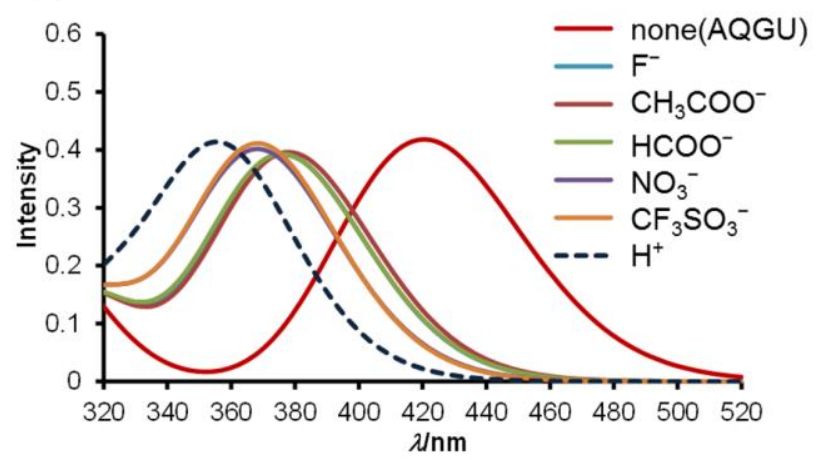

(f)

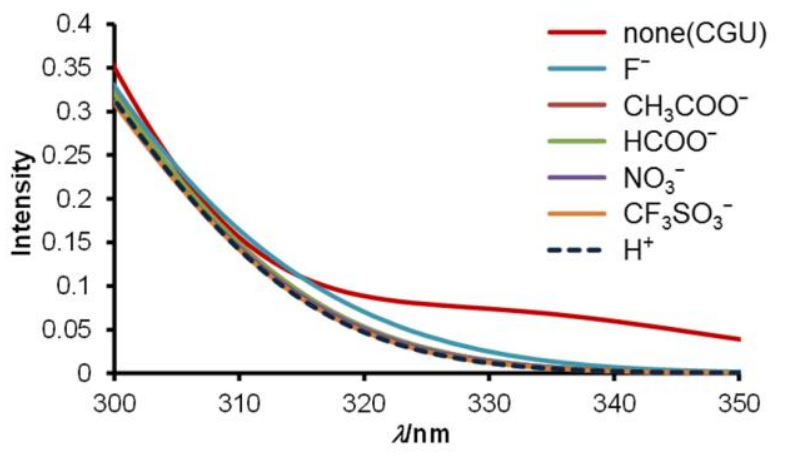

Figure 7. (left) The simulated absorption spectra of aryl guanidines (QGU, AQGU and CGU) in acetonitrile at the TD-CAM-B3LYP $(\omega=0.2) / 6-311+\mathrm{G}(\mathrm{d}, \mathrm{p})$ level of theory. The absorption spectra of protonated forms are given as dashed lines. (right) The comparison of the first weak absorption band of neutral guanidines and their salts with different counter ions. 
TD-CAM-B3LYP $(\omega=0.2)$ calculations predict the excitation energy of the first excited state in AQGU at $2.95 \mathrm{eV}$ and oscillator strength $f=0.210$. It corresponds to absorption around $420 \mathrm{~nm}$ (Figure 7c). Blue shift upon protonation amounts to $63 \mathrm{~nm}$, which is the largest value within the investigated series of chromophores. The absorption spectrum is more complicated in the region between 190 and $300 \mathrm{~nm}$. A dozen excited states contribute to this absorption band: (a) $E_{\mathrm{exc}}=$ $4.024 \mathrm{eV}, f=0.0726$; (b) $E_{\mathrm{exc}}=4.364 \mathrm{eV}, f=0.1365$; (c) $E_{\mathrm{exc}}=4.66 \mathrm{eV}, f=0.2948$; (d) $E_{\mathrm{exc}}=$ $5.14 \mathrm{eV}, f=0.17$; (e) $E_{\mathrm{exc}}=5.31 \mathrm{eV}, f=0.4799 ;(\mathrm{f}) E_{\mathrm{exc}}=5.53 \mathrm{eV}, f=0.1123 ;(\mathrm{g}) E_{\mathrm{exc}}=5.68$ $\mathrm{eV}, f=0.1859$; (h) $E_{\mathrm{exc}}=5.81 \mathrm{eV}, f=0.1517$. Roughly, two maxima around 268 and $232 \mathrm{~nm}$ as well as extended tail on the right (Figure 7c) are expected.

In the calculated spectrum of CGU (Figure 7e), two maxima can be observed as the main feature $\left(\lambda_{\max }=284 \mathrm{~nm}\right.$ and $\left.\lambda_{\max }=240 \mathrm{~nm}\right)$. Absorption associated to excitation from the ground state to the first excited state (HOMO-LUMO transition) does not appear as a separate weak band as found for all other guanidines. Instead, it contributes to a long tail $(360>\lambda>310 \mathrm{~nm})$ connected with the stronger band positioned at $280 \mathrm{~nm}$. Protonation shifts the HOMO-LUMO transition to the higher energies and it is completely hidden under the strong band with $\lambda_{\max }=277 \mathrm{~nm}$. Very small difference in UV spectra of neutral and protonated CGU renders this compound practically insensitive to the presence of anions in the region 300-350 $\mathrm{nm}$ (Figure 7e).

As was already discussed, the most stable tautomer of the neutral form in QGU, AQGU and CGU has imino nitrogen on one of two distant nitrogen atoms within the guanidine subunit, while the $\alpha$ - nitrogen bears the proton involved in the intramolecular hydrogen bond. The guanidine is coplanar with the chromophore, while the lone pair at the imino nitrogen atom is directed toward $\mathrm{H}(\mathrm{C} 2)$ hydrogen atom, additionally stabilizing the structure by $\mathrm{N}$...HC 
unclassical hydrogen bond. Since the lone pair lies on the $\sigma$ plane, the dominant interaction is between the highest occupied fragment orbital of the chromophore and the $\pi$ orbital of guanidine subunit (Figure 8). Fragment orbital interaction is similar as discussed for the aryl guanidines (PHGU, NGU ACGU), with destabilization being somewhat stronger in the case of anthraquinone and quinoline derivatives with respect to their naphthalene and anthracene counterparts.

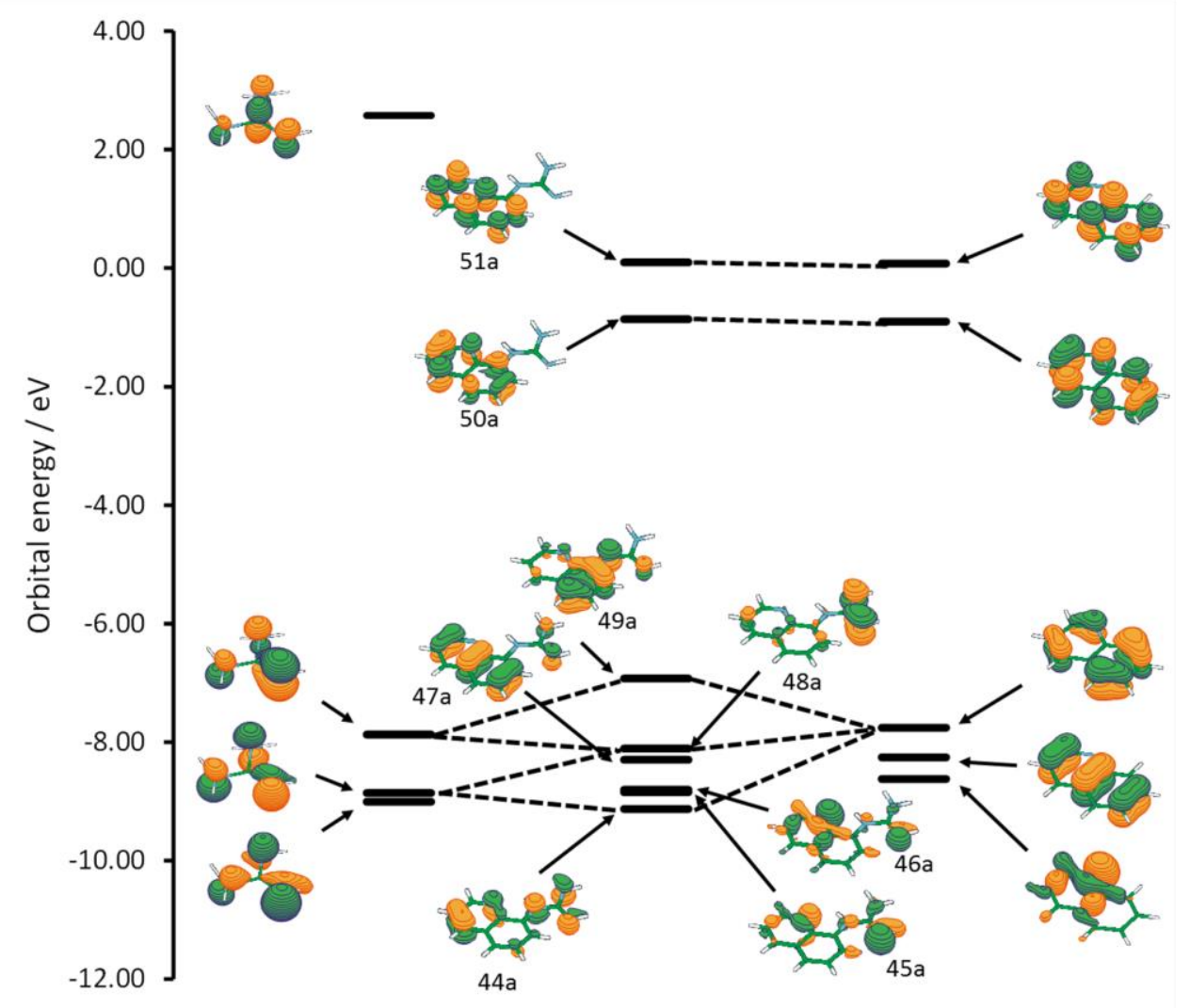

Figure 8. Orbital interactions in QGU. The energies were taken from CAM-B3LYP $(\omega=0.2) / 6$ $311+\mathrm{G}(\mathrm{d}, \mathrm{p})$ calculation in acetonitrile.

We note that the HOMO of 1-guanidylanthraquinone is strongly localized within the ring bearing the substituent, while the protonation induces an electron density shift toward the farthest 
anthraquinone ring. On the other hand, no such dramatic redistribution of the electron density was observed for the LUMO. The localization of the HOMO in one ring implies large orbital coefficients around junction bond and makes it sensitive to the change in electronic properties of guanidine subunit. Namely, neutral guanidine acts as electron donating, while the guanidinium cation acts as electron withdrawing substituent. ${ }^{73}$ Consequently, protonation of 1 guanidylanthraquinone will stabilize the HOMO significantly more than the LUMO, resulting in the aforementioned largest hypsochromic effect within the investigated set of arylguanidines.

As discussed earlier, anion binding of the anthraquinone and quinoline derivatives occurs most likely at the "site 2 " position and therefore does not induce deprotonation at the $\mathrm{N} 9$ of the guanidinium fragment. Nevertheless, the anion binding effect on the UV spectra is only slightly smaller than for the naphthylguanidine derivative. Examination of the changes in the partial charges in AQGU upon acetate and nitrate binding indicates no conformational dependence on the extent of electron density transfer. Regardless of whether guanidine is in perpendicular or almost co-planar conformation with respect to the chromophore plane, the decrease in the partial charge amounts to 0.17 and 0.10 |e| for acetate and nitrate binding, respectively, indicating a minor effect of the guanidine conformation on the UV spectra. For these derivatives, binding of fluoride, acetate and formate anions is expected to lead to deprotonation of the guanidinium cation subunit resulting in regaining UV spectra of the neutral guanidine

\section{CONCLUSIONS}

$\mathrm{UV} / \mathrm{Vis}$ spectra of phenylguanidine (PHGU) in the gas phase and acetonitrile have been simulated by TD-DFT calculations. Several DFT hybrid and long-range corrected functionals (BMK, PBE0, M062X, $\omega$ B97XD, LC-BLYP, LC- $\omega$ PBE, and CAM-B3LYP) were tested with 
respect to CASPT2 calculations for the gas-phase. In addition, comparison with isoelectronic phenyl urea and related phenyltiourea were carried out. Results indicate that PBE0 and longrange functional CAM-B3LYP method with the $\omega$ parameter modified to $0.2 \mathrm{a}_{0}{ }^{-1}$ provide consistently good agreement between experimental and calculated UV spectra for neutral and protonated phenyl and naphthyl guanidines, as well as for their salts with $\mathrm{CH}_{3} \mathrm{COOH}, \mathrm{HCOOH}$, $\mathrm{HNO}_{3}, \mathrm{HF}$ and $\mathrm{CF}_{3} \mathrm{SO}_{3} \mathrm{H}$.

UV spectra were also calculated for the series of aryl guanidines, in which the influence of the guanidine moiety on the UV spectra of the selected basic chromophore substructure (anthracene, anthraquinone, quinoline, and coumarine) was analyzed. All investigated guanidine derivatives showed HOMO-LUMO transition to be sensitive to protonation/deprotonation process. The observed changes in UV spectra upon protonation were interpreted in terms of changes in orbital interactions, conformational changes and presence/absence of intramolecular hydrogen bonds.

It was shown that the preferential binding site of anion involves interaction with the most acidic $\mathrm{NH}$ bond, which is the one closest to the aromatic moiety unless it is involved in the intramolecular hydrogen bond. Different response of the phenyl and naphthylguanidine toward acetate anion was observed, indicating formation of the ionic complex in the former case and deprotonation in the latter. That was attributed to the differences in $\mathrm{p} K_{\mathrm{a}}$ and stability of these two modes of the salt substructure. The less basic formate anion forms an ionic complex with 1naphthylguanidine without deprotonation, as deduced from the comparison of the experimental and calculated UV spectra.

Although anion binding induces elongation of the associated $\mathrm{NH}$ bonds, calculations predict minimal effect of the "partial deprotonation" to the UV spectra changes. These changes are 
mostly associated with charge compensation upon anion binding. The second, even larger in its extent, contribution is "neutralization", where complete proton transfer to anion takes place forming nonionic acid-base associate. Although, the dynamic situation is present in solution, we have shown that both situations are distinguishable and could be recognized from the UV spectra.

\section{ASSOCIATED CONTENT}

Supporting Information. Synthetic procedures and details of $\mathrm{p} K_{\mathrm{a}}$ measurements, excitation energies, oscillator strengths and leading configurations at CASPT2, CAM-B3LYP $(\omega=0.2)$ and PBE0 levels of theory, CASSCF active orbitals, relaxed and semi rigid scan for the formation of phenylguanidinium acetate salt, AIM calculation on NGU, Cartesian coordinates of optimized structures. This material is available free of charge via the Internet at http://pubs.acs.org.

\section{AUTHOR INFORMATION}

\section{Corresponding Author}

* Electronic mail: iantol@emma.irb.hr

\section{ACKNOWLEDGMENT}

The work was supported by the Croatian Science Foundation grant No. 9310. The calculations were performed on the Isabella cluster (isabella.srce.hr) at the Zagreb University Computing Center (SRCE). Funds for Germany-Croatia bilateral collaboration from the German Academic Exchange Service (DAAD, Project 54368738) and Ministry of Science, Education and Sports (Project: Optimizing bidirectional "highway" for photoactive response through guanidinechromophore junction) are also acknowledged. MB thanks the support of the A*MIDEX grant 
( ${ }^{\circ}$ ANR-11-IDEX-0001-02) and of the project Equip@Meso (ANR-10-EQPX-29-01), both funded by the French Government "Investissements d'Avenir" program.

\section{REFERENCES}

1. Li, Z.-T.; Wu, L.-Z. (Eds.) Hydrogen Bonded Supramolecular Structures, in Lecture Notes in Chemistry, Vol 87, Springer-Verlag, Berlin Heidelberg, 2015.

2. Puglisi, J. D.; Chen, L.; Frankel A. D.; Williamson, J. R. Role of RNA Structure in Arginine Recognition of TAR RNA. Proc. Natl. Acad. Sci. U.S.A. 1993, 90, 3680-3684.

3. Pavletich, N. P.; Pabo, C. O. Zinc Finger-DNA Recognition: Crystal Structure of a Zif268-DNA Complex at 2.1 A. Science 1991, 252, 809-817

4. Berg, J. M. Zinc Finger Domains: From Predictions to Design. Acc. Chem. Res. 1995, 28, $14-$ 19.

5. Howell, E. E.; Villafranca, J. E.; Warren, M. S.; Oatley, S. J.; Kraut, J. Functional Role of Aspartic Acid-27 in Dihydrofolate Reductase Revealed by Mutagenesis. Science 1986, 231, 1123 1128.

6. Crane, B. R.; Siegel, L. M.; Getzoff, E. D. Sulfite reductase structure at 1.6 A: evolution and catalysis for reduction of inorganic anions. Science 1995, 270, 59-60.

7. Kirby, J. P.; Roberts, J. A.; Nocera, D. G. Significant Effect of Salt Bridges on Electron Transfer. J. Am. Chem. Soc. 1997, 119, 9230-9236.

8. Amendola, V.; Fabbrizzi, L.; Mosca, L. Anion Recognition by Hydrogen Bonding: Urea-Based Receptors. Chem. Soc. Rev. 2010, 39, 3889-3915. and references cited therein. 
9. Li, A.-F.; Wang, J.-H.; Wang, F.; Jiang, Y.-B. Anion Complexation and Sensing Using Modified Urea and Thiourea-Based Receptors. Chem. Soc. Rev. 2010, 39, 3729-3745.

10. Zhang, S.; Echegoyen, L. Selective Anion Sensing by a Tris-Amide CTV Derivative: 1H NMR Titration, Self-Assembled Monolayers, and Impedance Spectroscopy. J. Am. Chem. Soc. 2005, $127,2006-2011$.

11. Chmielewski, M. J.; Jurczak, J. Anion Recognition by Neutral Macrocyclic Amides. Chem. Eur. J. 2005, 11, $6080-6094$.

12. Gupta, V. K.; Singh, L. P.; Chandra, S.; Kumar, S.; Singh, R.; Sethi, B. Anion Recognition Through Amide-Based Dendritic Molecule: A Poly(Vinyl Chloride) Based Sensor for Nitrate Ion. Talanta 2011, 85, 970-974.

13. Nieto, D.; Gonzáles-Vadillo, A. M.; Bruña, S.; Pastor, C. J.; Kaifer, A. E.; Cuadrado, I. Pt(II)Activated Coupling of Aminoethylferrocene with Benzonitrile. A Facile Access Route to a New Redox-Active Bis(ferrocenyl-amidine) Anion Sensor. Chem. Commun, 2011, 47, 10398-10400.

14. Schmuck, C.; Kuchelmeister, H. Y. Guanidinium Based Anion Receptors in Mirsky, V. M.; Yatsimirsky, A. K. (Eds.) Artificial Receptors for Chemical Sensors, Viley-VCH, Weinheim, Germany, 2011, 273-317.

15. Schug, K. A.; Lindner, W. Noncovalent Binding between Guanidinium and Anionic Groups: Focus on Biological- and Synthetic-Based Arginine/Guanidinium Interactions with Phosph[on]ate and Sulf[on]ate Residues. Chem. Rev. 2005, 105, 67-113.

16. Best, M. D.; Tobey, S. L.; Anslyn, E. V. Abiotic Guanidinium Containing Receptors for Anionic Species. Coord. Chem. Rev. 2003, 240, 3-15. 
17. Evans, L. S.; Gale, P. A.; Light, M. E.; Quesada, R. Anion Binding vs. Deprotonation in Colorimetric Pyrrolylamidothiourea Based Anion Sensors. Chem. Commun. 2006, 965-967.

18. Wu, F.-Y.; Hu, M.-H.; Wu, Y.-M.; Tan, X.-F.; Zhao, Y.-Q., Ji, Z.-J. Fluoride-Selective Colorimetric Sensor Based on Thiourea Binding Site and Anthraquinone Reporter. Spectrochim. Acta A 2006, 65, 633-637.

19. Jimenez, D.; Martinez-Manez, R.; Sancenon, F.; Soto, J. Selective Fluoride Sensing Using Colorimetric Reagents Containing Anthraquinone and Urea or Thiourea Binding Sites. Tetrahedron Lett. 2002, 43, 2823-2825.

20. Nishizawa, S.; Kato, R.; Hayashita, T.; Teramae, N. Anion Sensing by a Thiourea Based Chromoionophore via Hydrogen Bonding. Anal. Sci. 1998, 14, 595-597.

21. Margetić, D. in Ishikawa, T. (Ed.), Superbases for Organic Synthesis: Guanidines, Amidines, Phosphazenes and Related Organocatalysts, Wiley, Chichester, 2009, pp. 9-48.

22. Hall, N.F.; Sprinkle, M.R. Relations between the Structure and Strength of Certain Organic Bases in Aqueous Solution. J. Am. Chem. Soc. 1932, 54, 3469-3485.

23. Blondeau, P.; Segura, M.; Pérez-Fernández, R.; de Mendoza, J. Molecular Recognition of Oxoanions Based on Guanidinium Receptors. Chem. Soc. Rev. 2007, 36, 198-210.

24. Houk, R. J. T.; Tobey, S. L.; Anslyn, E. V. Abiotic Guanidinium Receptors for Anion Molecular Recognition and Sensing. Top. Curr. Chem. 2005, 255, 199-229.

25. Bose, P.; Nisar, B.; Ghosh, P. Functionalized Guanidinium Chloride Based Colourimetric Sensors for Fluoride and Acetate: Single Crystal X-ray Structural Evidence of -NH Deprotonation and Complexation. Org. Biomol. Chem. 2011, 9, 1972-1979. 
26. Sączewski, F.; Balewski, Ł. Biological Activities of Guanidine Compounds, 2008 - 2012 Update. Expert Opin. Ter. Pat. 2013, 23, 965-995.

27. Ferris, J.P.; Zamek, O.S.; Atbuch, A.M.; Freiman, H. Synthesis of Pyrimidines from Guanidine and Cyanoacetaldehyde. J. Mol. Evol. 1974, 3, 301-309.

28. Robertson, M.P.; Levy, M.; Miller, S.L. Prebiotic Synthesis of Diaminopyrimidine and Thiocytosine. J. Mol. Evol. 1996, 43, 543-550.

29. Vazdar, M.; Uhlig, F.; Jungwirth, P. Like-Charge Ion Pairing in Water: An Ab Initio Molecular Dynamics Study of Aqueous Guanidinium Cations. J. Phys. Chem. Lett. 2012, 3; 2021-2024.

30. Becke, A.D. Density-Functional Thermochemistry. III. The Role of Exact Exchange. J. Chem. Phys. 1993, 98, 5648.

31. Lee, C.; Yang, W.; Parr, R.G. Development of the Colle-Salvetti Correlation-Energy Formula into a Functional of the Electron Density. Phys. Rev. B 1988, 37, 785.

32. Runge, E.; Gross, E.K.U. Density-Functional Theory for Time-Dependent Systems. Phys. Rev. Lett. 1984, 52, 997.

33. Boese, A.D.; Martin, J.M.L. Development of Density Functionals for Thermochemical Kinetics. J. Chem. Phys. 2004, 121, 3405.

34. Adamo, C.; Barone, V. Toward Reliable Density Functional Methods without Adjustable Parameters: The PBE0 Model. J. Chem. Phys. 1999, 110, 6158.

35. Zhao, Y.; Truhlar, D.G. The M06 Suite of Density Functionals for Main Group Thermochemistry, Thermochemical Kinetics, Noncovalent Interactions, Excited States, and 
Transition Elements: Two New Functionals and Systematic Testing of Four M06-Class Functionals and 12 Other Functionals. Theor. Chem. Acc. 2008, 120, 215-241.

36. Chai, J. D.; Head-Gordon, M. Long-Range Corrected Hybrid Density Functionals with Damped Atom-Atom Dispersion Corrections. Phys. Chem. Chem. Phys. 2008, 10, 6615-6620.

37. Becke, A.D. Density-Functional Exchange-Energy Approximation with Correct Asymptotic Behavior. Phys. Rev. A 1988, 38, 3098-3100.

38. Iikura, H.; Tsuneda, T.; Yanai, T.; K. Hirao, K. A Long-Range Correction Scheme for Generalized-Gradient-Approximation Exchange Functionals. J. Chem. Phys. 2001, 115, 35403544 .

39. Perdew, J.P.; Burke, K.; Ernzerhof, M. Generalized Gradient Approximation Made Simple. Phys. Rev. Lett. 1996, 77, 3865-3868.

40. Vydrov, O.A.; Heyd, J.; Krukau, A.V.; Scuseria, G.E. Importance of Short-Range Versus Long-Range Hartree-Fock Exchange for the Performance of Hybrid Density Functionals. J. Chem. Phys. 2006, 125, 074106.

41. Yanai, T.; Tew, D.P.; Handy, N.C. A New Hybrid Exchange-Correlation Functional Using the Coulomb-Attenuating Method (CAM-B3LYP). Chem. Phys. Lett. 2004, 393, 51-57.

42. Laurent, D.; Jacquemin, D. TD-DFT Benchmarks: A Review. Int. J. Quantum Chem. 2013, 113, 2019-2039 and references therein.

43. Zhang, C.R.; Sears, J. S.; Yang, B.; Aziz, S. G.; Coropceanu, V.; Brédas, J.-L. Theoretical Study of the Local and Charge-Transfer Excitations in Model Complexes of Pentacene-C60 Using 
Tuned Range-Separated Hybrid Functionals. J. Chem. Theory Comput. 2014, 10, 2379-2388 and references $12,17,50$ and 51 therein.

44. Andersson, K.; Malmqvist, P.-Å.; Roos, B. O.; Sadlej, A.J.; Wolinski, K. Second-Order Perturbation Theory with a CASSCF Reference Function. J. Phys. Chem. 1990, 94, 5483-5488.

45. Andersson, K.; Malmqvist, P.-Å.; Roos, B.O. Second-Order Perturbation Theory with a Complete Active Space Self-Consistent Field Reference Function. J. Chem. Phys. 1992, 96, 1218.

46. Dunning, Jr., T. H. Gaussian Basis Sets for Use in Correlated Molecular Calculations. I. The Atoms Boron Through Neon and Hydrogen. J. Chem. Phys. 1989, 90, 1007.

47. Forsberg, N.; Malmqvist, P.-Å. Multiconfiguration Perturbation Theory with Imaginary Level Shift. Chem. Phys. Lett. 1997, 274, 196-204.

48. Ghigo, G.; Roos, B.O.; Malmqvist, P.-Å. A Modified Definition of the Zeroth-Order Hamiltonian in Multiconfigurational Perturbation Theory (CASPT2). Chem. Phys. Lett. 2004, 396, 142-149.

49. Antol, I.; Glasovac, Z.; Crespo-Otero, R.; Barbatti, M. Guanidine and Guanidinium Cation in the Excited State - Theoretical Investigation. J. Chem. Phys. 2014, 141, 074307.

50. Malmqvist, P.-Å.; Roos, B.O. The CASSCF State Interaction Method. Chem. Phys. Lett. 1989, $155,189-194$.

51. Miertuš, S.; Scrocco, E.; Tomasi, J. Electrostatic Interaction of a Solute with a Continuum. A Direct Utilizaion of Ab Initio Molecular Potentials for the Prevision of Solvent Effects. Chem. Phys. 1981, 55, 117-129. 
52. Frisch, M. J.; Trucks, G. W.; Schlegel, H. B.; Scuseria, G. E.; Robb, M. A.; Cheeseman, J. R.;

Scalmani, G.; Barone, V.; Mennucci, B.; Petersson, G. A. et al, Gaussian 09, revision D.01; Gaussian, Inc.: Wallingford, CT, 2009.

53. Boys, S.B.; Bernardi, F. The Calculation of Small Molecular Interactions by the Differences of Separate Total Energies. Some Procedures with Reduced Errors. Mol. Phys. 19 (1970) 553-566.

54. Simons, J.; Jørgensen, P.; Taylor, H.; Ozment, J. Walking on Potential Energy Surfaces. J. Phys. Chem. 1983, 87, 2745-2753.

55. Aquilante, F.; Vico, L.D.; Ferré, N.; Ghigo, G.; Malmqvist, P.-Å.; Neogrády, P.; Pedersen, T.B.; Pitonak, M.; Reiher, M.; Roos, B.O. et. al. MOLCAS 7: The Next Generation. J. Comput. Chem. 2010, 31, 224-247.

56. Veryazov, V.; Widmark, P.O.; Serrano-Andrés, L.; Lindh, R.; Roos, B.O. 2MOLCAS as a Development Platform for Quantum Chemistry Software. Int. J. Quantum Chem. 2004, 100, 626635.

57. Karlström, G.; Lindh, R.; Malmqvist, P.-Å.; Roos, B.O.; Ryde, U.; Veryazov, V.; Widmark, P.O.; Cossi, M.; Schimmelpfennig, B.; Neogrády, P.; Seijo, L. MOLCAS: a Program Package for Computational Chemistry. Comput. Mater. Sci. 2003, 28, 222-239.

58. Pedretti, A.; Villa, L.; Vistoli, G. VEGA: a Versatile Program to Convert, Handle and Visualize Molecular Structure on Windows-based PCs. J. Mol. Graph. 2002, 21, 47-49.

59. Schaftenaar, G.; Noordik, J.H. Molden: a Pre- and Post-Processing Program for Molecular and Electronic Structures. J. Comp. Aided Mol. Design 2000, 14, 123-134. 
60. Phenylguanidine is commercially available in the form of the carbonate salt. Nevertheless, to develop a general method for the guanilation applicable to vide variety of aromatic amines, we also prepared phenyl guanidine using the described method.

61. Rasmussen, C. R.; Villani Jr, F. J.; Weaner, L. E.; Reynolds, B. E.; Hood, A. R.; Hecker, L. R.; Nortey, S. O.; Hanslin, A.; Constanzo, M. J.; Powell, E. T.; Molinari, A. J. Improved Procedures for the Preparation of Cycloalkyl-, Arylalkyl-, and Arylthioureas. Synthesis, 1988, $1988,456-459$.

62. Shinada, T.; Umezawa, T.; Ando, T.; Kozuma, H.; Ohfune, Y. A New Entry for the Synthesis of $N$-Acyl- $N^{\prime}$-substituted Guanidines. Tetrahedron Lett. 2006, 47, 1945-1947.

63. Tomasi, J.; Mennuci, B.; Cammi, R. Quantum Mechanical Continuum Solvation Models. Chem. Rev. 2005, 105, 2999-3094.

64. Cossi, M.; Barone, V. Time-Dependent Density Functional Theory for Molecules in Liquid Solutions. J. Chem. Phys. 2001, 115, 4708.

65. Barbatti, M.; Aquino, A.J.A.; Lischka, H. The UV Absorption of Nucleobases: Semi-Classical Ab Initio Spectra Simulations. Phys. Chem. Chem. Phys. 2010, 12, 4959-4967.

66. Raczyńska, E.D.; Cyrański, M. K.; Gutowski, M.; Rak, J.; Gal, J.-F.; Maria, P.-C.; Darowska, M.; Duczmal, K. Consequences of Proton Transfer in Guanidine. J. Phys. Org. Chem. 2003, 16, $91-106$.

67. Housecroft, C.E.; Sharpe, A.G. Inorganic Chemistry, 2nd ed., Pearson Education Limited, Essex, 2005. p 171. 
68. Guthrie, J.P. Hydrolysis of Esters of Oxy Acids: $\mathrm{p} K_{\mathrm{a}}$ Values for Strong Acids; Brønsted Relationship for Attack of Water at Methyl; Free Energies of Hydrolysis of Esters of Oxy Acids; and a Linear Relationship Between Free Energy of Hydrolysis and $\mathrm{p} K_{\mathrm{a}}$ Holding Over a Range of 20 pK Units. Can. J. Chem. 1978, 56, 2342-2354.

69. CRC Handbook of Chemistry and Physics, 84th Edition (2004)

70. Muckerman, J. T.; Skone, J. H.; Ning, M.; Wasada-Tsutsui, Y. Toward the Accurate Calculation of $\mathrm{p} K_{\mathrm{a}}$ Values in Water and Acetonitrile. Biochim. Biophys. Acta - Bioenerg. 2013, $1827,882-891$.

71. Different basis set used for the partial optimization of each point along the scan causes a small bathochromic shift $(0.2-0.4 \mathrm{eV})$ in the excitation energies. The shift is systematic and does not affect trends and results.

72. Koch, U.; Popelier, P. L. A. Characterization of C-H-O Hydrogen Bonds on the Basis of the Charge Density. J. Phys. Chem. 1995, 99, 9747-9754.

73. Leffek, K. T.; Pruszynski, P.; Thanapaalasinngham, K. Basicity of Substituted 2-Phenyl1,1,3,3- tetramethylguanidines and Other Bases in Acetonitrile Solvent. Can. J. Chem. 1989, 67, $590-595$. 


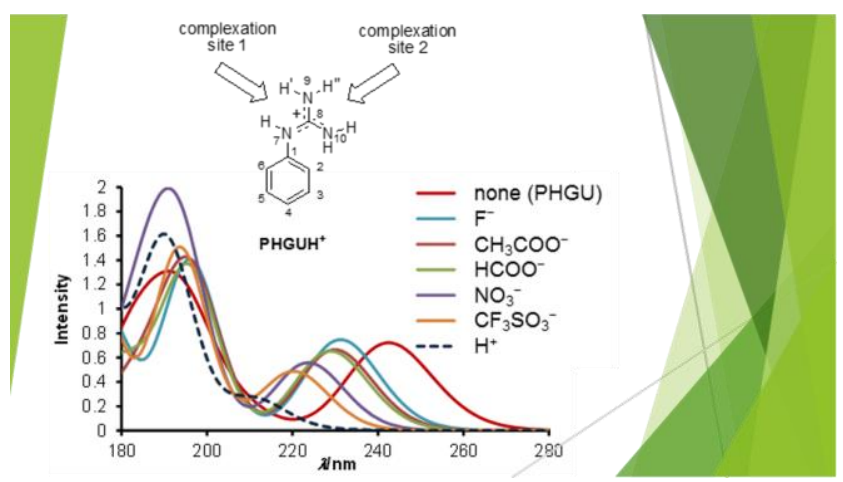

TOC graphic 